\title{
Effect of water on the dislocation creep microstructure and flow stress of quartz and implications for the recrystallized grain size piezometer
}

\author{
Michael Stipp, ${ }^{1}$ Jan Tullis, ${ }^{2}$ and Harald Behrens ${ }^{3}$ \\ Received 27 May 2005; revised 14 November 2005; accepted 27 December 2005; published 5 April 2006.
}

[1] Deformation experiments on Black Hills quartzite with three different initial water contents (as-is, water-added, and vacuum-dried) were carried out in the dislocation creep regime in order to evaluate the effect of water on the recrystallized grain size/flow stress piezometer. Samples were deformed in axial compression at temperatures of $750^{\circ}$ $1100^{\circ} \mathrm{C}$, strain rates between $2 \times 10^{-7} \mathrm{~s}^{-1}$ and $2 \times 10^{-4} \mathrm{~s}^{-1}$ and strains up to $46 \%$ using a molten salt assembly in a Griggs apparatus. An increase of the initial water content at otherwise constant deformation conditions caused a decrease in flow stress, an effect known as hydrolytic weakening. The total water content of the starting material was analyzed by Karl Fischer titration (KFT) and Fourier transform infrared (IR) spectroscopy, and quenched samples were analyzed microstructurally and by IR. Changes in the dynamic recrystallization microstructure correlate with changes in flow stress, but there is no independent effect of temperature, strain rate or water content. IR absorption spectra of the deformed spectra indicate that different water contents were maintained in the three sample sets throughout the experiments. However, the amounts of water measured within the vacuum-dried $\left(\sim 260 \pm 40 \mathrm{ppm} \mathrm{H}_{2} \mathrm{O}\right)$, the as-is $\left(\sim 340 \pm 50 \mathrm{ppm} \mathrm{H}_{2} \mathrm{O}\right)$, and the water-added $\left(\sim 430 \pm 110 \mathrm{ppm} \mathrm{H}_{2} \mathrm{O}\right)$ samples are significantly smaller than the initial content of the quartzite $\left(\sim 640 \pm 50 \mathrm{ppm} \mathrm{H}_{2} \mathrm{O}\right)$. Water from the inclusions in the starting material adds to the free fluid phase along the grain boundaries, which probably controls the water fugacity and the flow strength, but this water is largely lost during IR sample preparation. Vacuum-dried as well as water-added samples have the same recrystallized grain size/flow stress relationship as the piezometer determined for as-is samples. No independent effect of water on the piezometric relationship has been detected.

Citation: Stipp, M., J. Tullis, and H. Behrens (2006), Effect of water on the dislocation creep microstructure and flow stress of quartz and implications for the recrystallized grain size piezometer, J. Geophys. Res., 111, B04201, doi:10.1029/2005JB003852.

\section{Introduction}

[2] Since the work of Griggs and Blacic [1964, 1965] it is well known that the crystal plastic flow strength of "wet" quartz samples is much lower than that of "dry" samples deformed at the same conditions, and the general effect of water on dislocation creep microstructures has been documented [e.g., Hirth and Tullis, 1992], but its effect on the recrystallized grain size has not been quantified. The goal of our study was to determine whether water content has an independent effect on the recrystallized grain size-flow stress piezometer relation.

[3] The hydrolytic weakening effect is observed in experiments on single crystals [e.g., Griggs and Blacic,

\footnotetext{
${ }^{1}$ Geological Institute, Albert-Ludwigs-University, Freiburg, Germany.

${ }^{2}$ Department of Geological Sciences, Brown University, Providence, Rhode Island, USA.

${ }^{3}$ Institute of Mineralogy, Hannover University, Hannover, Germany.

Copyright 2006 by the American Geophysical Union. 0148-0227/06/2005JB003852\$09.00
}

1965; Bäeta and Ashbee, 1970; Hobbs et al., 1972; Balderman, 1974; Kekulawala et al., 1978; Linker and Kirby, 1981; Blacic and Christie, 1984; Kronenberg et al., 1986; also Paterson, 1989; Kronenberg, 1994] as well as polycrystalline aggregates such as novaculites and quartzites [e.g., Jaoul et al., 1984; Kronenberg and Tullis, 1984; Mainprice and Paterson, 1984; Koch et al., 1989; Hirth and Tullis, 1992; den Brok et al., 1994; Gleason and Tullis, 1995; Post and Tullis, 1998] and synthetic aggregates made from glass, silicic acid or silica gel [e.g., Paterson and Luan, 1990; Luan and Paterson, 1992]. The studies of Tullis et al. [1979], Kronenberg and Tullis [1984], and Tullis and Yund [1989] showed that hydrolytic weakening is pressure-dependent and that high confining pressures (approximately $\geq 1.0 \mathrm{GPa}$ ) are necessary at elevated laboratory strain rates to induce crystal plasticity in natural quartz aggregates. Taking the water and pressure dependence of the flow stress into account, Kohlstedt et al. [1995] postulated a water fugacity term in the power law constitutive relation for dislocation creep, and Post et al. [1996] verified experimentally that the flow strength is dependent 
on water fugacity $\left(\mathrm{H}_{2} \mathrm{O}\right)$ and not on $\mathrm{fH}_{2}, f \mathrm{O}_{2}$ or $a_{\mathrm{H}+}$, over the pressure range from 0.7 to $1.7 \mathrm{GPa}$. On the basis of these findings and well-constrained experimental flow law relations [Luan and Paterson, 1992; Gleason and Tullis, 1995] the strength of quartz-rich rocks can be extrapolated to crustal deformation conditions [e.g., Paterson and Luan, 1990; Hirth et al., 2001; Stipp et al., 2002a].

[4] For a direct measurement of rock strength in natural mylonites, the application of a paleopiezometer is required. The recrystallized grain size is the most reliable and most easily measurable microstructural feature to derive flow stresses from natural mylonites [e.g., Mercier et al., 1977; White, 1979; Kohlstedt and Weathers, 1980]. In a recent experimental study, a well-constrained recrystallized grain size piezometer for quartz [Stipp and Tullis, 2003] was calibrated using natural as-is quartzites; the use of a molten salt cell at high confining pressure $(1.5 \mathrm{GPa})$ in a Griggstype apparatus allowed good stress resolution [e.g., Green and Borch, 1989; Gleason and Tullis, 1993; Rybacki et al., 1998]. There has been some debate as to whether there is any independent effect of water on the recrystallized grain size piezometer. Two laboratory studies on olivine aggregates report contradictory results; Van der Wal et al. [1993] found that the recrystallized grain size piezometer is independent of the water content, whereas Jung and Karato [2001] observed a water dependence of the piezometer.

[5] In this study, we have investigated changes in the recrystallized grain size and other deformation microstructures of quartz within dislocation creep regimes 2 and 3 of Hirth and Tullis [1992] as a function of deformation temperature, strain rate, flow stress, and water content of the samples. Experiments were carried out in a molten salt assembly, allowing good stress resolution. For comparison with the previous study of Stipp and Tullis [2003] we also used Black Hills quartzite, but we changed the initial water content by adding water to or by vacuum drying the starting material. In that way we created two additional sample sets with different water contents, which we quantified using Fourier Transform Infrared spectroscopy.

\section{Methods}

\subsection{Deformation Experiments}

[6] Three sets of cylindrical samples of homogeneous whitish Black Hills quartzite (BHQ) with a length of $10 \mathrm{~mm}$ and a diameter of $5 \mathrm{~mm}$ were cored, cut to length, and the ends ground flat and perpendicular to the cylinder axis. BHQ has a grain size of approximately $100 \mu \mathrm{m}$, with $<1 \%$ impurities (mainly iron oxides) and $<1 \%$ porosity. All samples were wrapped in $\mathrm{Ni}$ foil with $\mathrm{Ni}$ disks on top and bottom prior to weld sealing in a Pt jacket. Ni serves as an internal oxygen fugacity buffer during the experiments. Asis and water-added samples were first heated on a hot plate for 12 hours at $120^{\circ} \mathrm{C}$, and as-is samples were weld sealed directly afterward. Water-added samples were put into the $\mathrm{Pt}$ can as two short cylinders, between which a drop of water $\left(0.20 \pm 0.01 \mathrm{wt} \%\right.$ distilled $\left.\mathrm{H}_{2} \mathrm{O}\right)$ was introduced by a pipette. The top of the water-added sample can was weld sealed while the whole can was immersed in a cold water bath. Vacuum-dried samples were weld sealed leaving only a small hole through which the internal water was driven out by vacuum heating at $800^{\circ} \mathrm{C}$ and approximately $6 \mathrm{~Pa}$. After
12 hours at these conditions the furnace was switched off and samples were left inside to cool down slowly under vacuum to room temperature over approximately 6 hours in order to minimize thermal cracking. Then the vacuum-dried samples were brought within seconds to atmospheric pressure and the remaining hole in the sample jacket was weld sealed immediately.

[7] Deformation experiments were carried out in axial compression in a Griggs apparatus at $1.5 \mathrm{GPa}$ using a molten salt cell (MSC); the sample assembly and experimental procedures were the same as those of Gleason and Tullis [1995] and Stipp and Tullis [2003]. The top $\mathrm{ZrO}_{2}$ (or $\mathrm{Al}_{2} \mathrm{O}_{3}$ ) and bottom $\mathrm{ZrO}_{2}$ pistons have a larger diameter $(\geq 6.35 \mathrm{~mm})$ than the sample, allowing homogeneous sample strain for shortening up to $45 \%$. Depending on deformation temperatures two different salt mixtures (eutectic composition at 1 bar) were used for the molten salt surrounding the sample jacket: $0.71 \mathrm{~g} \mathrm{NaCl}: 1.00 \mathrm{~g} \mathrm{KCl}$ was used for deformation at $1000^{\circ}$ to $1100^{\circ} \mathrm{C}$ and $0.81 \mathrm{~g}$ $\mathrm{LiCl}: 1.00 \mathrm{~g} \mathrm{KCl}$ was used for $750^{\circ}$ to $950^{\circ} \mathrm{C}$ (Tables 1 , 2 , and 3); melting points of these salt mixtures at $1.5 \mathrm{GPa}$ are $900-950^{\circ} \mathrm{C}$ and approximately $600^{\circ} \mathrm{C}$ [Rybacki et al., 1998], respectively.

[8] The differential stress measured externally includes the sample strength, the confining pressure and frictional stresses due to advancement of the $\sigma_{1}$ piston. In order to derive the flow stresses we have made corrections for the increasing confining pressure and the frictional stresses. The pressure increase (always $<100 \mathrm{MPa}$ ) was monitored during the experiments and subtracted from the corresponding differential stress. The friction correction for the as-is samples is described by Stipp and Tullis [2003]. For the vacuum-dried and water-added samples the method of friction correction based on repeated runs [cf. Gleason and Tullis, 1993] could not be applied since variable amounts of water loss during welding of the sample jackets may have led to variable sample strengths. Hence we used the friction correction method described by Rybacki et al. [1998], which assumes that friction during the deformation is given by a linear extrapolation of the initial load increase prior to the hit point. The reported error estimates for the flow stress include the maximum stress variation over the steady state range and the uncertainty of the extrapolation of the initial load increase prior to the hit point. In addition, there was commonly a friction decrease after 30-35\% strain, as the $\sigma_{1}$ tungsten carbide piston passed through the upper graphite disk (compare MSC assembly in Figure 1 of Stipp and Tullis [2003]). This friction decrease is also considered in the error estimation, as is noise in the data recording.

[9] The first $2-5 \%$ strain of the stress-strain curves includes not only the elastic strength of the sample and presumably some initial plastic deformation, but also some deformation of the top and bottom $\mathrm{Pt}$ and $\mathrm{Ni}$ jacket discs. Reliable corrections can only be made for the differential stress after the yield. Therefore the initial parts of all the stress-strain records should not be compared from one run to another.

\subsection{Sample Characterization}

[10] Microstructural characterization and grain size measurements were carried out on ultrathin sections $(\sim 5-$ 
Table 1. Experimental Deformation Conditions and Recrystallized Grain Size Data for the "As-Is" Samples

\begin{tabular}{|c|c|c|c|c|c|c|c|}
\hline Sample & $\begin{array}{c}\text { Temp, } \\
{ }^{\circ} \mathrm{C}\end{array}$ & $\begin{array}{c}\text { Time at } \mathrm{P} \\
\text { and } \mathrm{T} \text {, hours }\end{array}$ & $\begin{array}{c}\text { Strain Rate, } \\
\mathrm{s}^{-1}\end{array}$ & $\begin{array}{c}\text { Axial Strain, } \\
\%\end{array}$ & $\begin{array}{c}\text { Flow Stress, } \\
\mathrm{MPa}\end{array}$ & $\begin{array}{c}\text { Recrystallized } \\
\text { Grain Size, } \mu \mathrm{m}\end{array}$ & $\begin{array}{l}\text { Number } \\
\text { of Grains }\end{array}$ \\
\hline W-1126 - $\beta$ & 1100 & 253.83 & & 17 & & $46 \pm 15$ & 734 \\
\hline W-1116 - $\beta$ & 1100 & 319.80 & $2.1-2.3 \times 10^{-7}$ & 21 & $34 \pm 16$ & & \\
\hline W-1066 - $\beta$ & 1100 & 52.67 & & 31 & & $18.0 \pm 5.5$ & 676 \\
\hline W-1096 - $\beta$ & 1100 & 62.93 & $2.0-2.5 \times 10^{-6}$ & 32 & $60 \pm 15$ & & \\
\hline$W-1022-\beta$ & 1100 & 16.38 & $0.8-1.0 \times 10^{-6}$ & 30 & $130 \pm 30$ & $12.1 \pm 3.6$ & 804 \\
\hline W-1029- $\beta$ & 1100 & 22.12 & & 46 & & $9.0 \pm 2.4$ & 876 \\
\hline W-1102 - $\beta$ & 1100 & 18.05 & $2.1-2.8 \times 10^{-5}$ & 33 & $130 \pm 13$ & & \\
\hline W-1119- $\beta$ & 1100 & 16.07 & $1.8-2.5 \times 10^{-4}$ & 36 & $257 \pm 35$ & $3.4 \pm 0.9$ & 931 \\
\hline W-1025 - $\beta$ & 1050 & 58.67 & $1.8-2.4 \times 10^{-6}$ & 32 & $87 \pm 17$ & $13.6 \pm 4.0$ & 476 \\
\hline W-1024- $\beta$ & 1000 & 59.75 & & 22 & & $11.6 \pm 3.2$ & 568 \\
\hline $\mathrm{W}-1101-\beta$ & 1000 & 63.53 & $1.8-2.3 \times 10^{-6}$ & 29 & $102 \pm 9$ & & \\
\hline W-1051 - $\beta$ & 1000 & 10.67 & $1.9-2.9 \times 10^{-5}$ & 41 & $189 \pm 30$ & $4.6 \pm 1.1$ & 638 \\
\hline W-1050 - $\alpha$ & 900 & 68.87 & & 34 & & $5.0 \pm 1.3$ & 620 \\
\hline W-1099- $\alpha$ & 900 & 68.00 & $2.0-2.7 \times 10^{-6}$ & 33 & $149 \pm 18$ & & \\
\hline W-1049 - $\alpha$ & 900 & 19.78 & $1.8-2.8 \times 10^{-5}$ & 44 & $268 \pm 40$ & $3.2 \pm 0.7$ & 777 \\
\hline W-1085- $\alpha$ & 850 & 57.92 & $1.9-2.6 \times 10^{-6}$ & 32 & $198 \pm 30$ & $4.6 \pm 1.3$ & 918 \\
\hline W-1030 - $\alpha$ & 800 & 71.77 & $1.8-2.4 \times 10^{-6}$ & 32 & $207 \pm 38$ & $4.4 \pm 1.1$ & 651 \\
\hline
\end{tabular}

${ }^{a}$ Sample letter $\alpha$ and $\beta$ refer to quartz stability field. Repeated runs for microstructure and mechanical data are listed within the same row. Time at $P$ and $\mathrm{T}$ consists of the prehit duration (from a few hours to almost 2 days for W-1116/W-1126) as well as the deformation time; for the friction experiments it also includes the hit cycle at faster strain rate after the deformation ( $\sim 0.5$ hour). The instantaneous strain rate increase over the interval from $10 \%$ to the final strain is indicated. The error estimation of the recrystallized grain size is displayed as 1 standard deviation. The number of recrystallized grains measured in each sample is given. See text and Stipp and Tullis [2003] for further explanations.

$15 \mu \mathrm{m})$ using light optical microscopy. Computer-integrated polarization (CIP) microscopy [e.g., Panozzo Heilbronner and Pauli, 1993] was applied to identify grain boundary outlines (Figure 1). Sample sites with a minimum of impurities were selected along the sample center axis parallel to the compression direction. From each of these sites an orientation image color-coded by the quartz $c$ axis orientation was produced by CIP. This CIP image was stacked together with a circular-polarized image and three crossed polarized images in different rotation positions (input images from CIP), the azimuth image, a misorientation image, and other output images from CIP (Figure 1). Grain boundary outlines were drawn and digitized based on the CIP image and the whole image stack, hence utilizing differences in $c$ axis orientation as well as the optically visible grain boundaries.

[11] Recrystallized grains were distinguished from porphyroclasts visually and from bimodal grain size distributions. The size of each grain was calculated using the public domain NIH Image program (developed at the U.S. National Institutes of Health and available at http://rsb.info.nih.gov/ nih-image/). Labeling in NIH Image allows one to keep track of the size of each grain during the whole procedure of grain size processing (Figure 1). The diameter of each recrystallized grain is defined as the diameter of a circle with the same area, and the average two-dimensional recrystallized grain size for each sample was calculated as the root-mean-square diameter from all measured recrystallized grains in that sample. Errors are given as 1 standard deviation. The average grain sizes and numbers of measured grains are given in Tables 1,2 , and 3 .

[12] Fourier transform infrared (IR) spectroscopy was used to determine the total content of water-related species in the deformed samples and in the starting material. Thick sections were cut along the cylinder axis and polished on both sides. The thickness of the sections ranged from 0.065 to $0.198 \mathrm{~mm}$ (Table 4) and was measured using a digital micrometer with a precision of $\pm 2 \mu \mathrm{m}$. Spectra were recorded in the range $500-5000 \mathrm{~cm}^{-1}$ using an IR microscope IRscope II attached to a Bruker IFS88 FTIR spectrometer. A globar light source, a $\mathrm{KBr}$ beam splitter and a DTGS detector were used. One hundred scans per spectrum were accumulated with a spectral resolution of $2 \mathrm{~cm}^{-1}$. Depending on the sample size we used a circular aperture with a diameter of 2, 3, or $4 \mathrm{~mm}$. For quantification of water contents, spectra were baseline corrected using a flexicurve generated with the software package OPUS of Bruker. The baseline is constructed by fitting a polynomial in the ranges $5000-3900 \mathrm{~cm}^{-1}$ and $2600-2300 \mathrm{~cm}^{-1}$.

[13] Karl Fischer titration (KFT) was used to determine the initial content of water-related species of the starting

Table 2. Experimental Deformation Conditions and Recrystallized Grain Size Data for the "Water-Added" Samples

\begin{tabular}{|c|c|c|c|c|c|c|c|}
\hline Sample & $\begin{array}{c}\text { Temp, } \\
{ }^{\circ} \mathrm{C}\end{array}$ & $\begin{array}{c}\text { Time at } \\
\mathrm{P} \text { and } \mathrm{T}, \text { hours }\end{array}$ & $\begin{array}{l}\text { Strain Rate, } \\
\mathrm{s}^{-1}\end{array}$ & $\begin{array}{c}\text { Axial Strain, } \\
\%\end{array}$ & $\begin{array}{c}\text { Flow Stress, } \\
\text { MPa }\end{array}$ & $\begin{array}{l}\text { Recrystallized } \\
\text { Grain Size, } \mu \mathrm{m}\end{array}$ & $\begin{array}{l}\text { Number } \\
\text { of Grains }\end{array}$ \\
\hline W-1172 - $\beta$ & 1000 & 63.93 & $2.0-2.5 \times 10^{-6}$ & 29 & $48 \pm 11$ & $19.3 \pm 5.1$ & 834 \\
\hline $\mathrm{W}-1142-\beta$ & 950 & 62.48 & $1.8-2.3 \times 10^{-6}$ & 29 & $66 \pm 16$ & $13.3 \pm 4.7$ & 736 \\
\hline W-1081 - $\alpha$ & 900 & 56.63 & $1.9-2.7 \times 10^{-6}$ & 33 & $139 \pm 24$ & $6.9 \pm 2.0$ & 464 \\
\hline W-1089- $\alpha$ & 850 & 51.12 & $2.1-2.7 \times 10^{-6}$ & 31 & $177 \pm 35$ & $4.9 \pm 1.2$ & 539 \\
\hline W-1082 - $\alpha$ & 800 & 68.92 & $1.9-2.9 \times 10^{-6}$ & 41 & $168 \pm 50$ & $4.9 \pm 1.5$ & 548 \\
\hline W-1140 - $\alpha$ & 750 & 75.75 & $1.9-2.4 \times 10^{-6}$ & 29 & $156 \pm 17$ & $5.2 \pm 1.5$ & 566 \\
\hline
\end{tabular}

${ }^{a}$ Sample letter $\alpha$ and $\beta$ refer to quartz stability field. Time at $P$ and $T$ consists of the prehit duration and the deformation time. The instantaneous strain rate increase over the interval from $10 \%$ to the final strain is indicated. The error estimation of the recrystallized grain size is displayed as 1 standard deviation. The number of recrystallized grains measured in each sample is given. See text for further explanations. 
Table 3. Experimental Deformation Conditions and Recrystallized Grain Size Data for the "Vacuum-Dried" Samples ${ }^{\mathrm{a}}$

\begin{tabular}{ccccccc}
\hline Sample & $\begin{array}{c}\text { Temp, } \\
{ }^{\circ} \mathrm{C}\end{array}$ & $\begin{array}{c}\text { Time at P } \\
\text { and T, hours }\end{array}$ & $\begin{array}{c}\text { Strain Rate, } \\
\mathrm{s}^{-1}\end{array}$ & $\begin{array}{c}\text { Axial Strain, } \\
\%\end{array}$ & $\begin{array}{c}\text { Flow Stress, } \\
\text { MPa }\end{array}$ & $\begin{array}{c}\text { Recrystallized } \\
\text { Grain Size, } \mu \mathrm{m}\end{array}$ \\
$\begin{array}{c}\text { Number } \\
\text { of Grains }\end{array}$ \\
W-1143 - $\beta$ & 1100 & 101.63 & $2.2 \times 10^{-7}$ & 7 & $58 \pm 18$ & $19.9 \pm 4.9$ \\
W-1141 - $\beta$ & 1100 & 62.50 & $1.9-2.4 \times 10^{-6}$ & 28 & $114 \pm 35$ & $8.3 \pm 2.2$ \\
W-1149 - $\beta$ & 1000 & 51.70 & $1.9-2.4 \times 10^{-6}$ & 25 & $247 \pm 40$ & $4.2 \pm 1.1$ \\
\hline
\end{tabular}

a Sample letter $\alpha$ and $\beta$ refer to quartz stability field. "Time at $\mathrm{P}$ and $\mathrm{T}$ " consists of the pre-hit duration and the deformation time. The instantaneous strain rate increase over the interval from $10 \%$ to the final strain is indicated. The error estimation of the recrystallized grain size is displayed as 1-standard deviation. The number of recrystallized grains measured in each sample is given. See text for further explanations.

\section{Unprocessed photo micrographs}

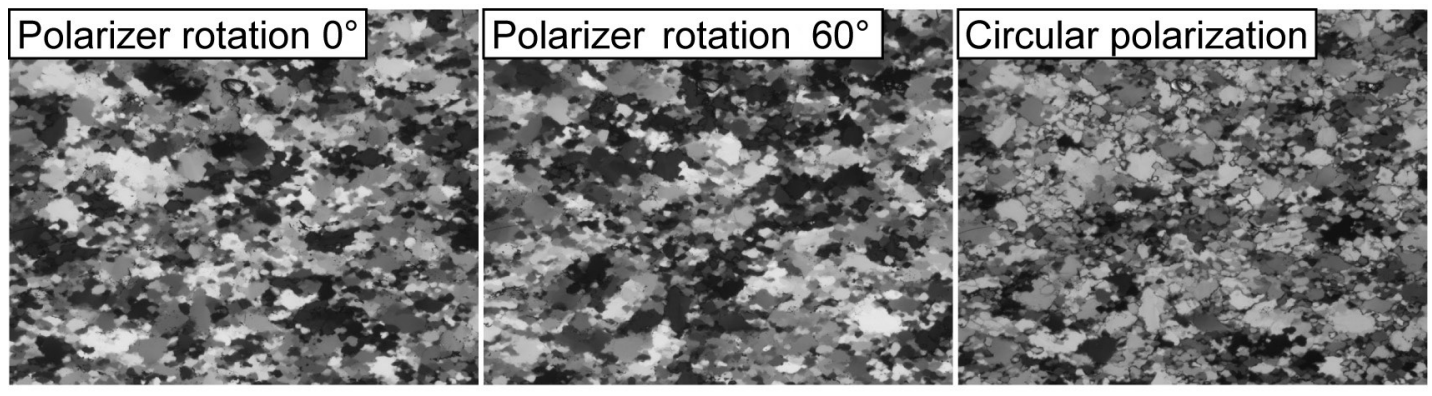

\section{CIP (Computer integrated polarization) microscopy output}

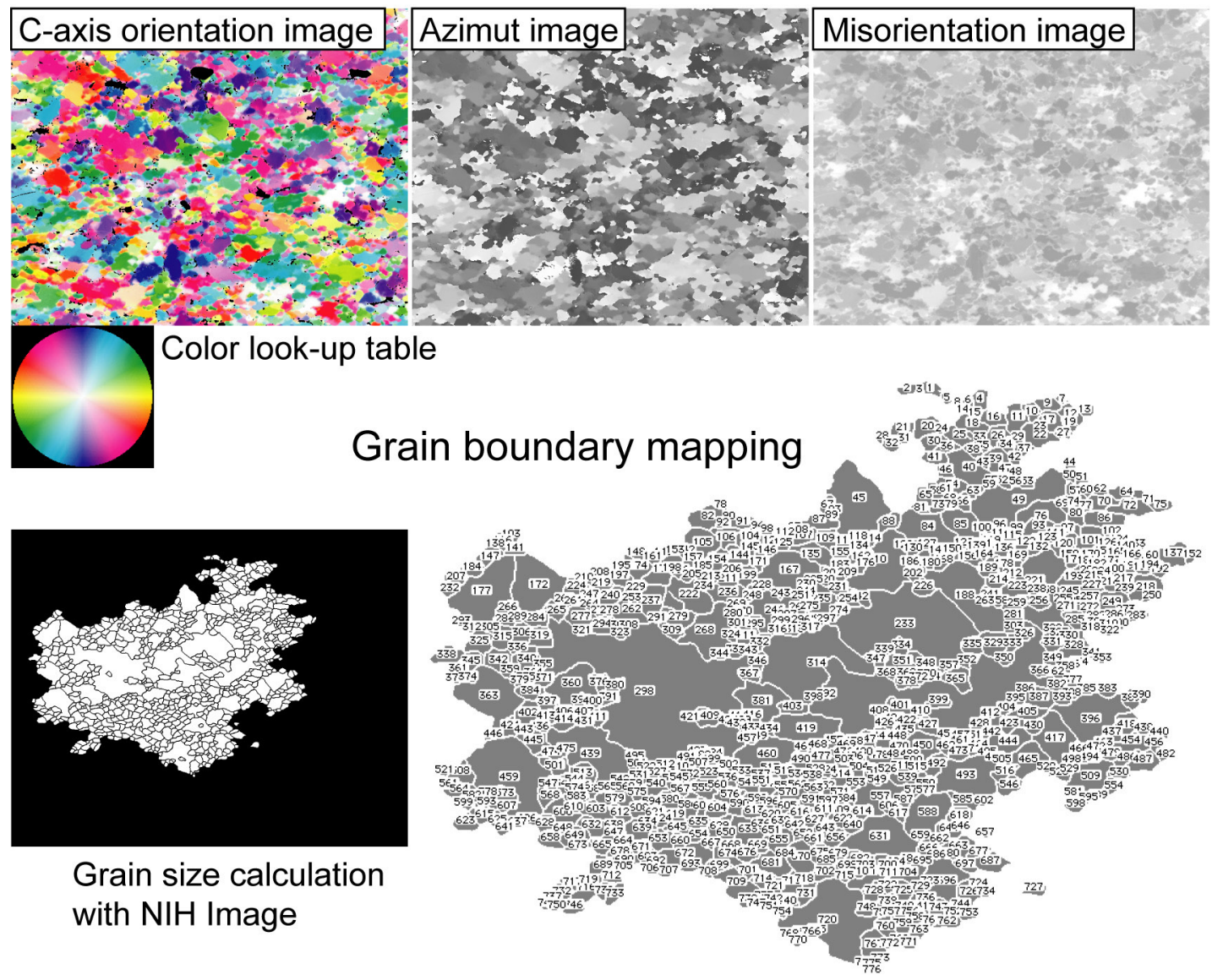

Figure 1. Method of grain size determination using computer integrated polarization (CIP) microscopy. A stack of CIP input and output images is used to digitize grain boundary outlines. Originally, the $c$ axis orientation image is in color and based on a color look-up table of the visible spectrum. From the digitized grain boundary maps, porphyroclasts and recrystallized grains can be indexed and separated, and grain sizes are determined using the public domain NIH Image program. The calculated 2-D grain size represents the diameter of a circle with an area equivalent to the grain area. 
Table 4. Fourier Transform Infrared Spectroscopy Analyses ${ }^{\mathrm{a}}$

\begin{tabular}{|c|c|c|c|c|c|c|}
\hline Sample & Assembly & $\begin{array}{l}\text { Deformation } \\
\text { Temperature }\end{array}$ & $\begin{array}{c}\text { Section } \\
\text { Thickness, } \mu \mathrm{m}\end{array}$ & $\begin{array}{c}\text { Paterson } \\
\text { [1982], } \\
\text { ppm } \mathrm{H}_{2} \mathrm{O}\end{array}$ & $\begin{array}{c}\text { Libowitzky and } \\
\text { Rossman } \\
\text { [1997], } \\
\text { ppm } \mathrm{H}_{2} \mathrm{O}\end{array}$ & $\begin{array}{c}\text { BHQ } \\
\text { Calibration, } \\
\text { ppm } \mathrm{H}_{2} \mathrm{O}\end{array}$ \\
\hline BHQ-1 & - & - & 148 & 374.5 & 543.9 & 693.8 \\
\hline BHQ-2 & - & - & 137 & 324.1 & 476.2 & 607.4 \\
\hline BHQ-3 & - & - & 141 & 469.8 & 483.0 & 616.2 \\
\hline Average & - & - & - & $389.5 \pm 74.0$ & $501.0 \pm 37.3$ & $639.1 \pm 47.5$ \\
\hline W-1143 & vacuum-dried & $1000^{\circ} \mathrm{C}$ & $101.5 \pm 3.2$ & 192.7 & 224.4 & 286.2 \\
\hline W-1149 & vacuum-dried & $1100^{\circ} \mathrm{C}$ & $100.8 \pm 12.9$ & $167.2 \pm 10.8$ & $183.2 \pm 5.7$ & $233.7 \pm 21.8$ \\
\hline Average & vacuum-dried & - & - & $180.0 \pm 18.0$ & $203.8 \pm 29.1$ & $260.0 \pm 37.2$ \\
\hline $\mathrm{W}-1050$ & as-is & $900^{\circ} \mathrm{C}$ & $178.2 \pm 10.2$ & $262.9 \pm 18.9$ & $271.1 \pm 3.8$ & $345.9 \pm 14.6$ \\
\hline W-1096 & as-is & $1100^{\circ} \mathrm{C}$ & $129.0 \pm 15.2$ & 252.2 & 241.7 & 308.3 \\
\hline W-1099 & as-is & $900^{\circ} \mathrm{C}$ & $197.8 \pm 13.4$ & 201.6 & 240.4 & 306.6 \\
\hline W-1101 & as-is & $1000^{\circ} \mathrm{C}$ & $176.0 \pm 9.0$ & 199.9 & 251.3 & 320.5 \\
\hline W-1102 & as-is & $1100^{\circ} \mathrm{C}$ & $191.6 \pm 7.5$ & $291.1 \pm 0.4$ & $337.0 \pm 1.1$ & $429.9 \pm 4.2$ \\
\hline W-1126 & as-is & $1100^{\circ} \mathrm{C}$ & $90.7 \pm 19.3$ & $239.8 \pm 25.5$ & $245.4 \pm 20.2$ & $313.1 \pm 77.3$ \\
\hline Average & as-is & - & - & $241.3 \pm 35.7$ & $264.5 \pm 37.3$ & $337.4 \pm 47.5$ \\
\hline W-1081 & $\mathrm{H}_{2} \mathrm{O}$-added & $900^{\circ} \mathrm{C}$ & $67.6 \pm 9.2$ & $377.2 \pm 27.5$ & $420.9 \pm 6.7$ & $536.9 \pm 25.5$ \\
\hline W-1082 & $\mathrm{H}_{2} \mathrm{O}$-added & $800^{\circ} \mathrm{C}$ & $131.2 \pm 7.9$ & 270.5 & 320.2 & 408.5 \\
\hline W-1089 & $\mathrm{H}_{2} \mathrm{O}$-added & $850^{\circ} \mathrm{C}$ & $122.4 \pm 10.6$ & $281.9 \pm 18.9$ & $284.2 \pm 2.3$ & $362.6 \pm 8.7$ \\
\hline W-1140 & $\mathrm{H}_{2} \mathrm{O}$-added & $750^{\circ} \mathrm{C}$ & $109.8 \pm 2.4$ & 365.7 & 433.0 & 552.3 \\
\hline W-1142 & $\mathrm{H}_{2} \mathrm{O}$-added & $950^{\circ} \mathrm{C}$ & $65.2 \pm 11.8$ & $259.8 \pm 15.4$ & $223.8 \pm 1.6$ & $285.5 \pm 6.1$ \\
\hline Average & $\mathrm{H}_{2} \mathrm{O}$-added & - & - & $311.0 \pm 55.9$ & $336.4 \pm 89.6$ & $429.2 \pm 114.3$ \\
\hline
\end{tabular}

${ }^{\mathrm{a}}$ Results from the water content determinations based on the absorption spectra, applying the calibrations of Paterson [1982], Libowitzky and Rossman [1997], and this work. Calibration data with error estimations (1 standard deviation) are calculated from two or three measurements with spot size of 2, 3, or $4 \mathrm{~mm}$ in diameter. Average values for the starting material and the deformed vacuum-dried, as-is, and water-added samples are indicated including the 1-standard deviation according to the different measurements. Results from the three calibrations show the same trends in water content for the whole sample set but vary considerably in absolute values. See text for discussion.

material (BHQ) for comparison with the IR analyses. Samples were heated to temperatures around $1230^{\circ} \mathrm{C}$ (Table 5), and the released water was transported with a dry argon stream into a titration cell where the amount of water was measured by coulometric titration using the Karl Fischer reaction. A detailed description of the apparatus and the method is given by Behrens et al. [1996]. Muscovite is used as a house standard, and the measured water content agrees within error with previous determinations.

[14] Prior to the KFT procedure, the BHQ samples were heated to $100-120^{\circ} \mathrm{C}$ for more than 24 hours to remove any adsorbed water. Because of the short analysis times of 5$10 \mathrm{~min}$, extraction of water from the sample may not be complete. For materials which do not form a melt during heating the extraction of water tends to be very efficient, although for water-poor materials such as quartzite complete extraction of water is difficult to verify. After KFT the BHQ samples were crumbly and less transparent than the starting material, and it was impossible to prepare a section for IR spectroscopy to quantify postanalytical water. Hence we have no direct proof of complete dehydration. However, the absence of melt after analysis and the brittle nature of the heating products imply that water could easily escape along grain boundaries and microcracks. Moreover, we expect that the internal pressure of the fluid inclusions in which most of the water is located (see IR results) is high enough at the analytical temperatures to open migration paths [e.g., Bodnar et al., 1989]. Hence we assume that no significant water remains in the sample except for a few very stable intragranular $\mathrm{OH}$ defects, and no correction was made for unextracted water. The error of the KFT analyses was estimated by error propagation considering the error of the sample weight (typically $0.1 \mathrm{mg}$ ) and the error of the titration rate $( \pm 0.02 \mu \mathrm{g}$ water per second $)$, based on reproducibility of analyses of hydrous minerals with stoichiometric composition [Behrens et al., 1996] (Table 5).

\section{Results}

\subsection{Mechanical Data}

[15] The deformed samples used in this study have an ideal cylindrical shape indicating homogeneous deformation and very low temperature gradients (Figure 2). Homogeneous sample strain is also suggested by the homogeneity of

Table 5. Karl Fischer Titration Data for BHQ Starting Material of Three Different Size Fractions ${ }^{\mathrm{a}}$

\begin{tabular}{lcccrr}
\hline \multicolumn{1}{c}{ Sample } & $\begin{array}{c}\text { Sample } \\
\text { Weight, mg }\end{array}$ & $\begin{array}{c}\text { Titration } \\
\text { Time, s }\end{array}$ & $\begin{array}{c}\text { T (Final), } \\
{ }^{\circ} \mathrm{C}\end{array}$ & $\begin{array}{c}\text { Blank } \\
(\text { Corrected) }\end{array}$ & $\begin{array}{c}\text { Weight } \\
\text { Percent } \mathrm{H}_{2} \mathrm{O}\end{array}$ \\
\hline Blank value 1 & - & 180.0 & 1230.0 & 30.80 & 0.00 \\
Muscovite & 19.54 & 397.0 & 1205.0 & 31.90 & 827.08 \\
BHQ, three pieces & 171.63 & 379.0 & 1210.0 & 33.16 & 110.23 \\
BHQ, crushed & 274.63 & 440.0 & 1230.0 & 34.38 & 183.22 \\
BHQ, single piece & 211.18 & 408.0 & 1220.0 & 35.57 & $0.064 \pm 0.004$ \\
Blank value 2 & - & 180.0 & 1230.0 & 34.70 & $0.067 \pm 0.003$ \\
\hline
\end{tabular}

${ }^{a}$ Corrections are made for blank values (measurements without samples), titration rate (extraction weight during temperature increase with time), and in comparison to a sample standard (muscovite from Spittal). Water contents are quite constant but vary slightly with particle size. See text for further explanations. 


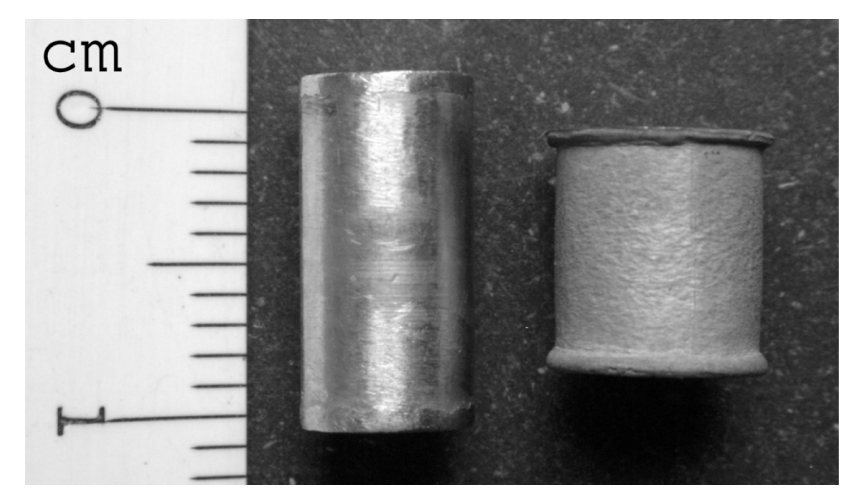

Figure 2. BHQ sample with surrounding $\mathrm{Pt} / \mathrm{Ni}$ jacket in undeformed and deformed (W-1029) state. Note the almost ideal cylindrical shape of both samples indicating homogeneous sample strain. The bulge on top and bottom of the deformed sample is due to the plastic deformation of the upper and lower disk of the Pt/Ni jacket.

the deformation microstructures throughout almost all of the samples (illustrated below).

[16] Most samples were quenched when the desired sample strain had been achieved, in order to preserve the steady state deformation microstructure. Two samples (W1049, W-1141) were quenched and taken out immediately after the sample jacket ruptured. Their microstructures are overprinted by some axial cracks and some marginal molten salt intrusion; however, the microstructures in the undisturbed sample areas are homogeneous and comparable to other samples at similar flow stress conditions. From other failed experiments we know that after jacket failure, $\sigma_{1}$ rapidly decreases to almost the value of the confining pressure, but W-1049 and W-1141 were stopped while the stress was still decreasing. For these reasons we assume that the dislocation creep microstructures in these two samples accurately reflect the flow stress, and we have used the data in our previous study [Stipp and Tullis, 2003] and in the present study.

[17] The experimental setup [Stipp and Tullis, 2003] allowed us to reach relatively high axial strains compared to previous studies with a MSC [e.g., Green and Borch, 1989; Gleason and Tullis, 1995; Rybacki et al., 1998; Renner et al., 2001; Rybacki et al., 2003]. However, many of the samples did not reach high strain, due to malfunctions of the assembly such as power or temperature fluctuations, or due to very slow strain rates. From the stress-strain records we are convinced that most samples used in this study achieved mechanical steady state (Figures $3 a$ and $3 b$ ).

[18] The twelve as-is samples (without repeated runs) were deformed at temperatures from 800 to $1100^{\circ} \mathrm{C}$, at strain rates between approximately $2 \times 10^{-4} \mathrm{~s}^{-1}$ and $2 \times$ $10^{-7} \mathrm{~s}^{-1}$, and reached axial shortening strains of 17 to $46 \%$ (Table 1). Steady state flow stresses range between $34 \pm 16$ and $268 \pm 40 \mathrm{MPa}$. Further details of the experimental results are described and discussed by Stipp and Tullis [2003] (compare their Figure 2).

[19] The six water-added samples range in temperature from 750 to $1000^{\circ} \mathrm{C}$, at relatively constant strain rates of approximately $2 \times 10^{-6} \mathrm{~s}^{-1}$ to $3 \times 10^{-6} \mathrm{~s}^{-1}$ and axial shortening strains between 29 and 41\% (Table 2). Flow stresses were taken in the interval between $10 \%$ and the final strain in accordance with Stipp and Tullis [2003] and vary between $48 \pm 11$ and $177 \pm 35 \mathrm{MPa}$ (Table 2 and Figure $3 a$ ). The flow stresses of the water-added samples are systematically lower than those of the as-is samples at otherwise comparable deformation conditions (temperature, strain rate, confining pressure; Tables 1 and 2); for example, at $1000^{\circ} \mathrm{C}, 48 \pm 11 \mathrm{MPa}(\mathrm{W}-1172)$ compared to $102 \pm 9 \mathrm{MPa}$ (W-1024). All of the water-added experiments were carried out at a constant displacement rate of approximately $2 \times 10^{-5} \mathrm{~mm} \mathrm{~s}^{-1}$. Hence flow stresses should systematically decrease with increasing temperature. This is true for the overall trend from a flow stress of $156 \pm$ $30 \mathrm{MPa}$ at $750^{\circ} \mathrm{C}$ to $48 \pm 11 \mathrm{MPa}$ at $1000^{\circ} \mathrm{C}$ (Table 2 and Figure 3a). In the range of $750^{\circ} \mathrm{C}$ to $850^{\circ} \mathrm{C}$, however, there is almost no difference and even a slight inverse trend, which might reflect the limits of our stress resolu-
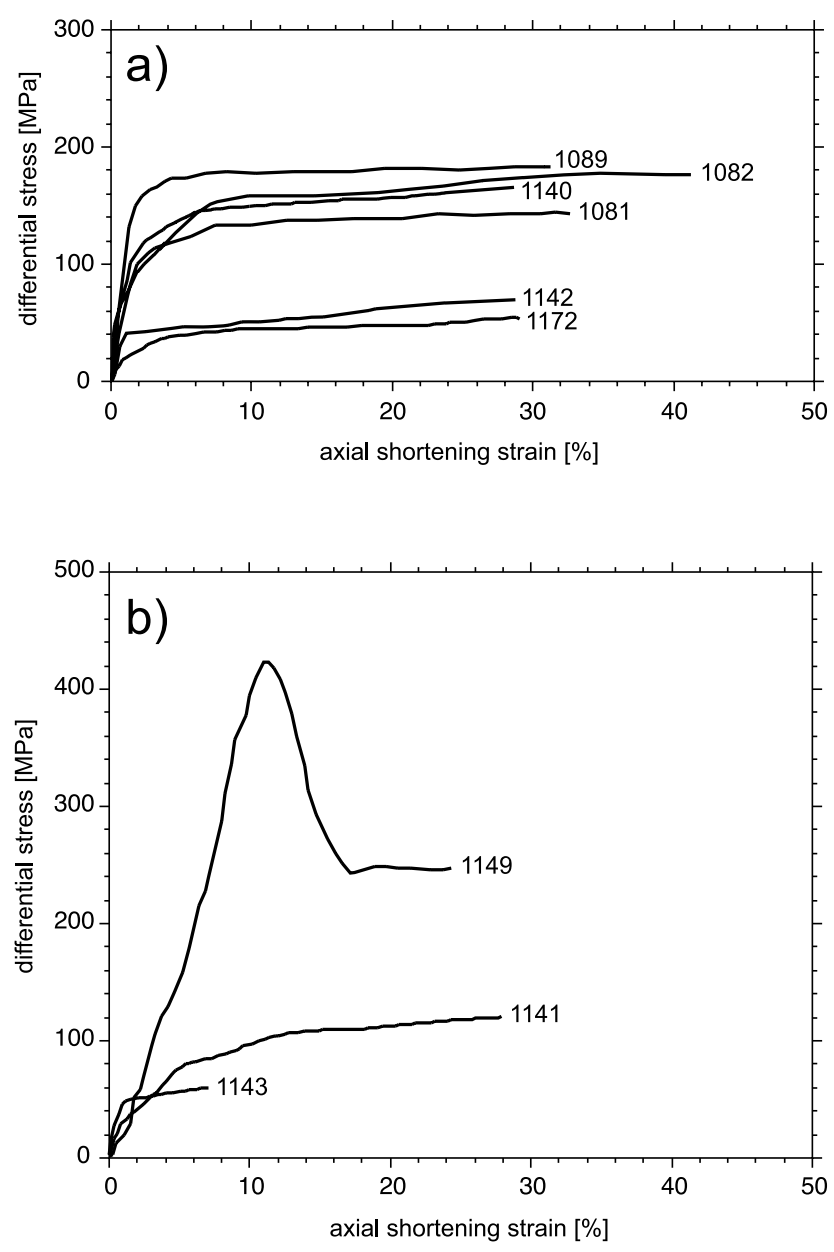

Figure 3. Stress/strain data and sample numbers for the MSC experiments on (a) water-added and (b) vacuum-dried BHQ. Friction corrections are described in the text. Flow stress values in Tables 2 and 3 are averaged from $10 \%$ strain until the end of each run except for samples W-1143 and W-1149 in Figure 3b; for W-1143 the flow stress was taken as the final differential stress and for W-1149 the flow stress was taken as the average over the interval from $17 \%$ to the final strain. 
tion, or differences in the amount of water lost during welding of the jackets (compare IR results and section 4).

[20] The three vacuum-dried samples were shortened 7 to $28 \%$ at temperatures of 1000 and $1100^{\circ} \mathrm{C}$ and strain rates of approximately $2 \times 10^{-6} \mathrm{~s}^{-1}$ and $2 \times 10^{-7} \mathrm{~s}^{-1}$ (Table 3). Flow stresses range between $58 \pm 18$ and $247 \pm 40 \mathrm{MPa}$ and were taken in accordance with Stipp and Tullis [2003] over the interval between $10 \%$ and the final strain for W-1141 but not for W-1143 and W-1149 (Table 3 and Figure 3b). The very slow strain rate sample $\mathrm{W}-1143$ failed due to a power surge after almost 3 days of deformation, at $7 \%$ shortening. We took the final differential stress $\Delta \sigma=58 \pm$ $18 \mathrm{MPa}$ before failure as the flow stress, knowing, however, from comparison with other runs that a further stress increase would probably have occurred. If the observed slope is extrapolated to the interval of 10 to $20 \%$ axial strain, an average $\Delta \sigma$ of approximately $70 \mathrm{MPa}$ would result, which is within the error of our estimation. $70 \mathrm{MPa}$ would be an upper limit, since it does not take into account the plateau of flow stress at strains $>10 \%$ which is observed in all other experiments of this study. W-1149 shows a strongly increasing differential stress up to $425 \mathrm{MPa}$ followed by an abrupt weakening down to a steady state flow stress of $247 \pm 40 \mathrm{MPa}$ after $17 \%$ strain (Figure $3 \mathrm{~b}$ ). This strain weakening behavior is typical for dislocation creep regime 1 described by Hirth and Tullis [1992]; they explain the strain hardening by dislocation tangling when climb is limited, and the strain weakening by initiation of bulging recrystallization at the grain boundaries. Mechanical steady state is reached after weakening and therefore we took the flow stress for W-1149 over the interval between $17 \%$ and the final strain.

\subsection{Recrystallization Microstructures}

[21] The recrystallized grain sizes from the as-is, wateradded, and vacuum-dried samples are listed in Tables 1, 2, and 3 , respectively. In this section we illustrate the deformation microstructures for these three sample sets, describe how they change with temperature, strain rate and flow stress, and relate them to the dislocation creep regimes described by Hirth and Tullis [1992].

[22] For as-is samples, we have documented the changes in recrystallization microstructure and grain size that occur with increasing deformation temperature (decreasing differential stress, Figures $4 \mathrm{a}-4 \mathrm{~d}$ ) or with decreasing strain rate (decreasing differential stress, Figures $4 \mathrm{e}-4 \mathrm{~h}$ ) at otherwise constant deformation conditions. The range of axial strains of 17 to $46 \%$ in these samples does not affect the microstructure (other than the percentage of recrystallization) as discussed by Hirth and Tullis [1992].

[23] The microstructures produced with increasing temperature at a strain rate of $\sim 2 \times 10^{-6} \mathrm{~s}^{-1}$ are illustrated in Figures $4 \mathrm{a}-4 \mathrm{~d}$. At $800^{\circ} \mathrm{C}$ porphyroclasts are slightly elongate, with undulose extinction, deformation lamellae and very small recrystallized grains along their sutured boundaries (Figure 4a). The width of the sutures is about the same as the diameter of the recrystallized grains. At $900^{\circ} \mathrm{C}$ the microstructure is similar (Figure 4b), although the porphyroclasts are less elongate. Both these microstructures are typical for dislocation creep regime 2 of Hirth and Tullis [1992]. At $1000^{\circ} \mathrm{C}$ the amount of recrystallization and the size of the recrystallized grains are significantly increased (Figure 4c).
Porphyroclasts have less undulose extinction, no deformation lamellae, and an equant shape. Most porphyroclasts are still recognizable, but have irregular and sutured grain boundaries due to irregular consumption by recrystallization; however, some are completely recrystallized. This microstructure is typical of regime 3 of Hirth and Tullis [1992]. At $1100^{\circ} \mathrm{C}$ the microstructure is similar (Figure 4d) although recrystallization has progressed further so that recrystallized grains and remnants of porphyroclasts cannot be distinguished. The grain size distribution is unimodal and not bimodal as in the other samples described above.

[24] The microstructures produced with decreasing strain rate at $1100^{\circ} \mathrm{C}$ are shown in Figures $4 \mathrm{e}-4 \mathrm{~h}$, from $2 \times$ $10^{-4} \mathrm{~s}^{-1}$ to $2 \times 10^{-7} \mathrm{~s}^{-1}$. The range of microstructures over these 3 orders of magnitude of strain rate is much greater than that shown in Figures $4 a-4 d$ for a temperature range of $300^{\circ} \mathrm{C}$. For example, microstructures of both the 800 and $900^{\circ} \mathrm{C} 10^{-6} \mathrm{~s}^{-1}$ samples (Figures $4 \mathrm{a}$ and $4 \mathrm{~b}$ ) are intermediate to those of the $1000^{\circ} \mathrm{C}, 10^{-4}$ and $10^{-5} \mathrm{~s}^{-1}$ samples (Figures $4 \mathrm{e}$ and $4 \mathrm{f}$ ). Figures $4 \mathrm{~d}$ (temperature series) and $4 \mathrm{~g}$ (strain rate series) are from the same sample $\left(1100^{\circ} \mathrm{C}, 10^{-6} \mathrm{~s}^{-1}\right)$. The microstructure produced at $1100^{\circ} \mathrm{C}$ and $2 \times 10^{-7} \mathrm{~s}^{-1}$ (Figure $4 \mathrm{~h}$ ) is characterized by large grains with straight grain boundaries and few or no intracrystalline deformation features. The grain size distribution is unimodal and recrystallized grains cannot be reliably distinguished from porphyroclasts.

[25] A comparison between the temperature and strain rate dependence of the recrystallization microstructures for as-is samples indicates that 1 order of magnitude change in strain rate has a much bigger effect than a $100^{\circ} \mathrm{C}$ change in temperature. This difference between the effects of temperature and strain rate can be seen by comparing samples $\mathrm{W}-1049\left(900^{\circ} \mathrm{C}, 2 \times 10^{-5} \mathrm{~s}^{-1}\right)$ and $\mathrm{W}-1119\left(1100^{\circ} \mathrm{C}, 2 \times\right.$ $10^{-4} \mathrm{~s}^{-1}$ ) from the regime $1 /$ regime 2 transition (Figure 5). Both samples have the same recrystallized grain size and the same flow stress within the error estimates. The microstructures display slightly elongate porphyroclasts with undulose extinction, deformation bands, and finely sutured grain boundaries. Along the grain boundaries small recrystallized grains have the same size as the sutures, indicative of local grain boundary migration and subgrain rotation recrystallization [cf. Drury et al., 1985; Stipp et al., 2002b]. The only microstructural difference between the two samples is that W-1049 has basal deformation lamellae while $\mathrm{W}-1119$ does not, suggesting that the formation of the lamellae is primarily related to temperature or to the $\alpha$ quartz field. W-1049 was deformed at $200^{\circ} \mathrm{C}$ lower temperature and 1 order of magnitude lower strain rate than $\mathrm{W}-1119$; thus it appears that for the recrystallization microstructure of as-is samples, 1 order of magnitude in strain rate is approximately equivalent to a temperature difference of $200^{\circ} \mathrm{C}$. Since both temperature and strain rate are related to the stress in the steady state flow law, and a decrease in flow stress is associated with either an increase in temperature or a decrease in strain rate at otherwise constant conditions, microstructural changes can directly be correlated to changes in the flow stress, and we will assume that correlation in the following microstructural description.

[26] The water-added (Figures 6a-6c) and the vacuumdried samples (Figures 6d-6f) display the same micro- 
a)

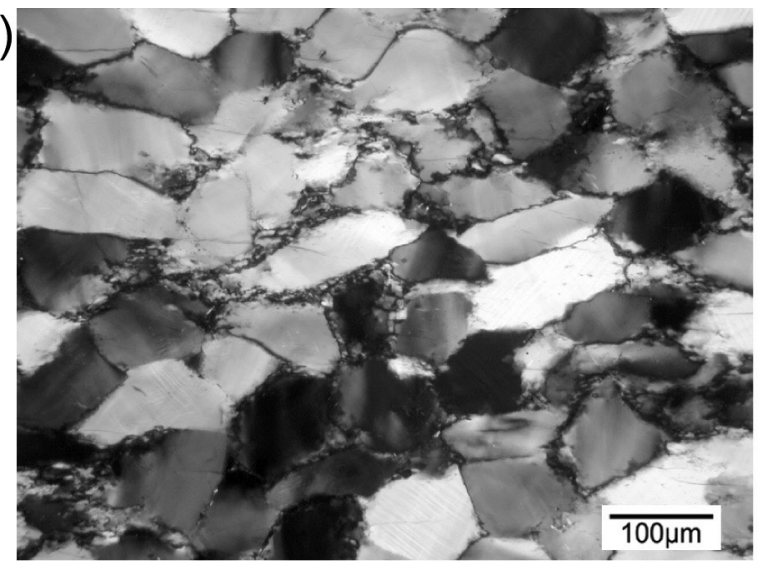

b)

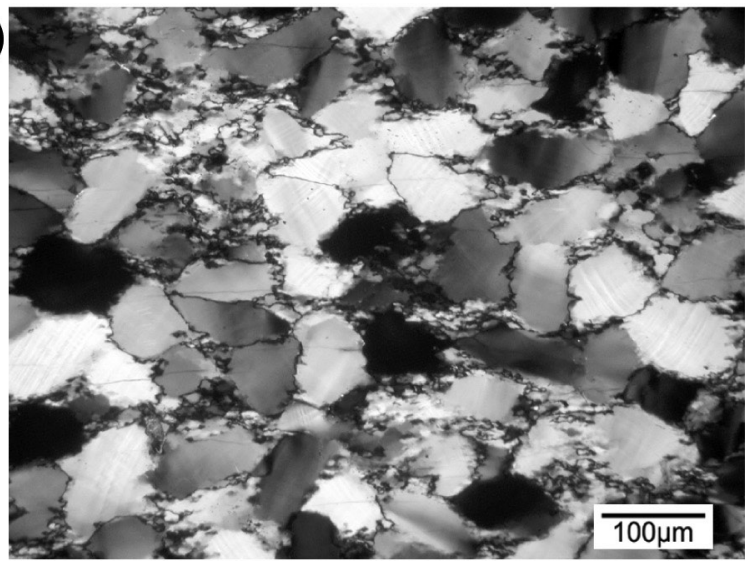

c)

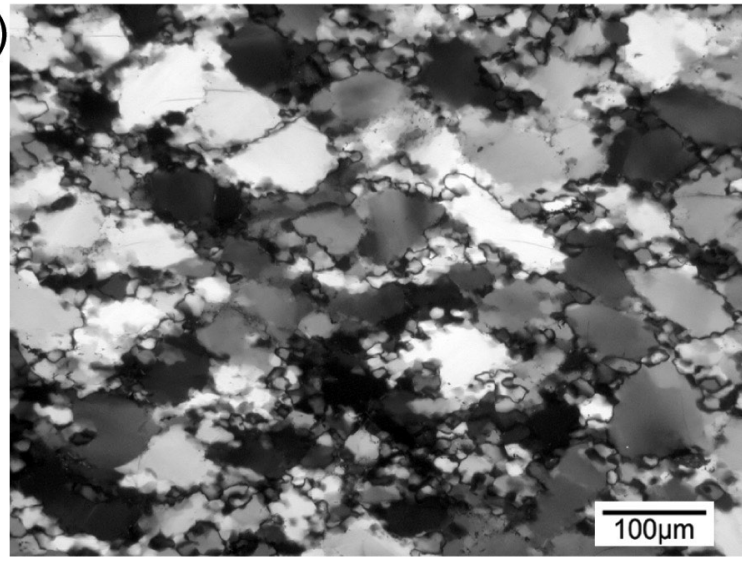

d)

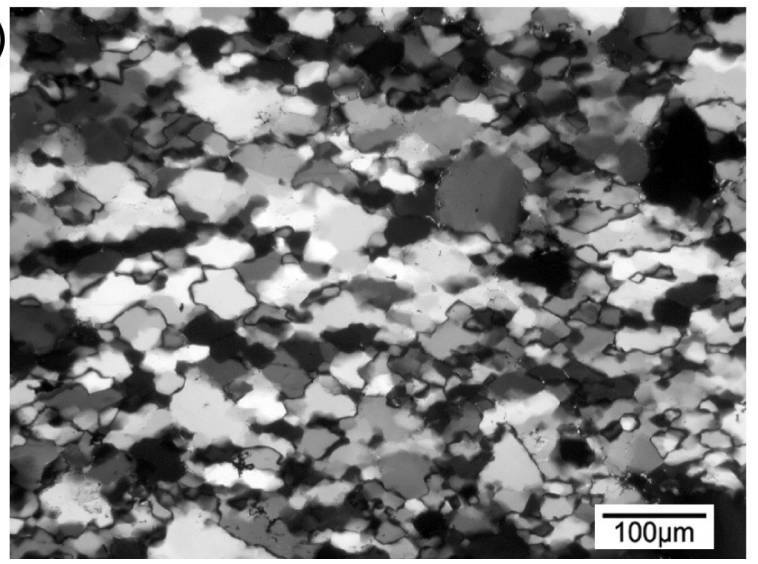

e)
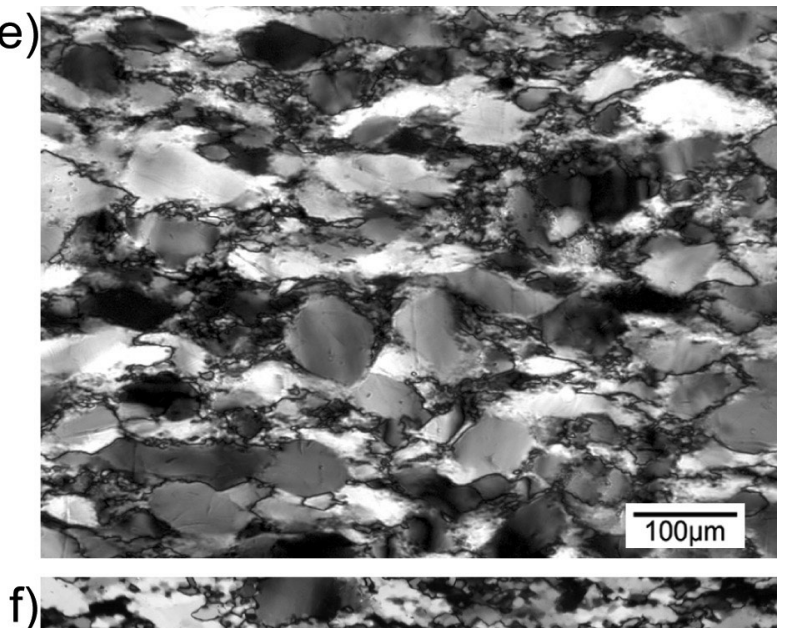

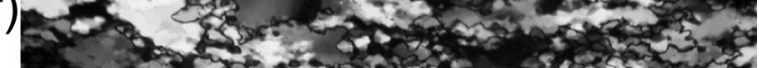

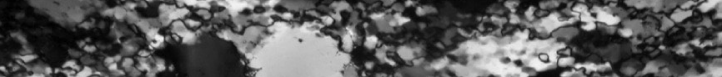

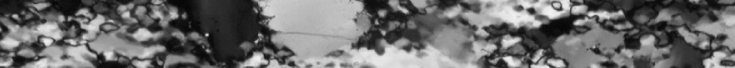

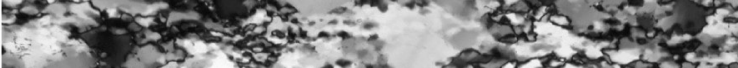

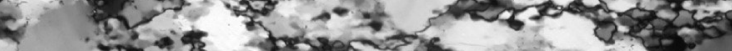

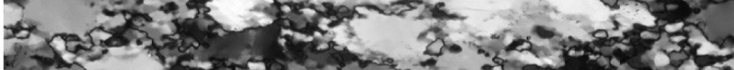

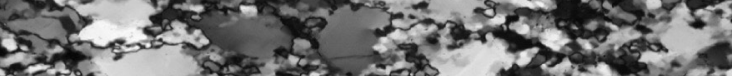

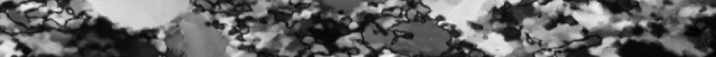

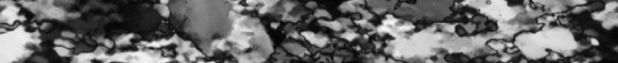

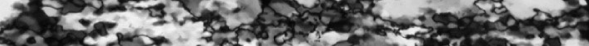

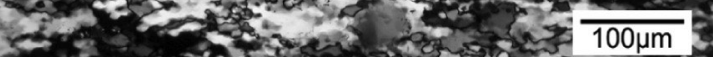
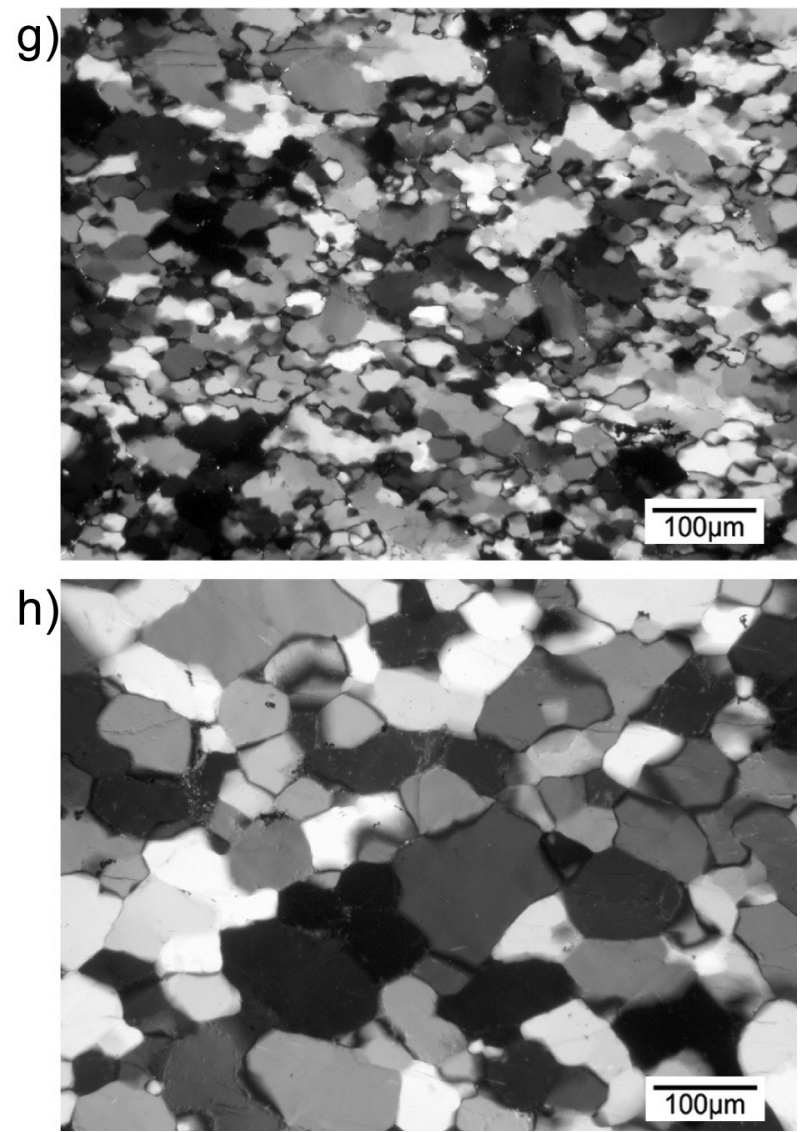

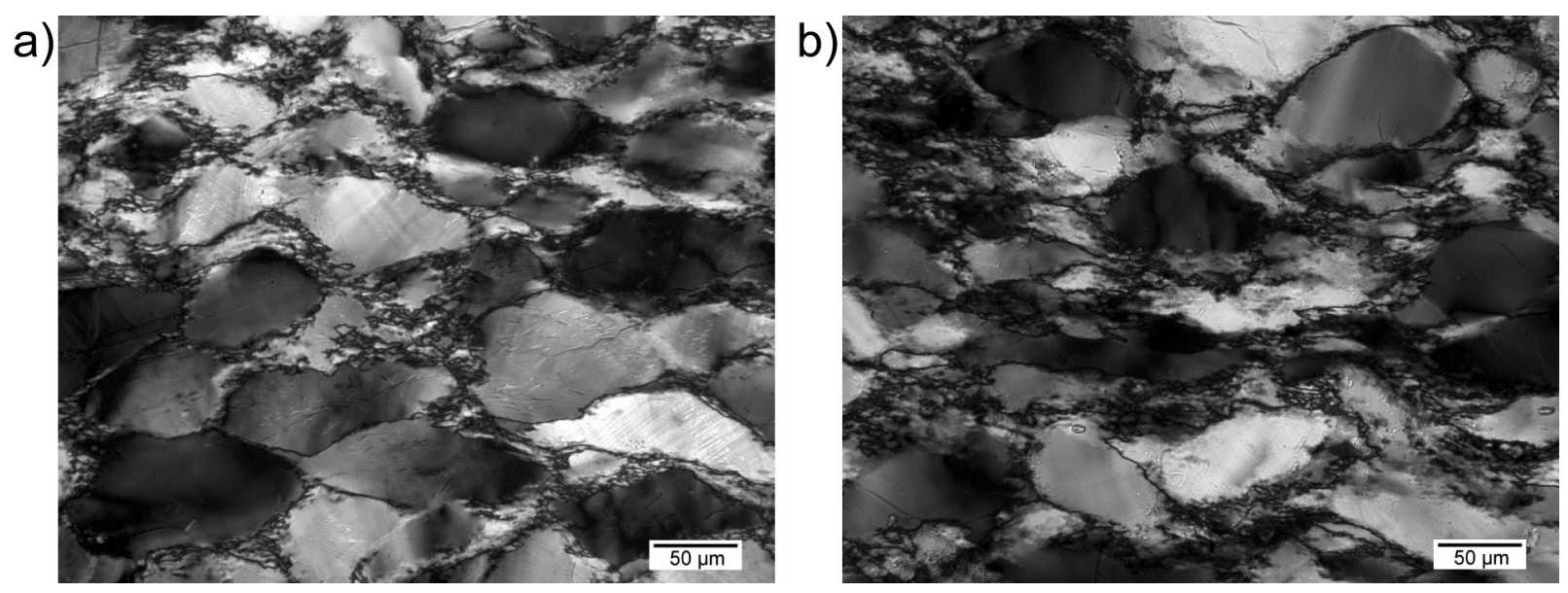

Figure 5. Microstructural comparison based on light optical micrographs (crossed polarizers; shortening direction vertical) of two as-is deformed BHQ samples. (a) Elongate porphyroclasts with undulose and patchy extinction, bulged grain boundaries, and small marginal subgrains and recrystallized grains (regime $1 / 2$ transition, sample W-1049) deformed at $900^{\circ} \mathrm{C}, \sim 2 \times 10^{-5} \mathrm{~s}^{-1}, 44 \%$ strain and a flow stress of $268 \pm 40 \mathrm{MPa}$. (b) Same microstructure from a sample deformed at $1100^{\circ} \mathrm{C}, \sim 2 \times 10^{-4} \mathrm{~s}^{-1}$, $36 \%$ strain and a flow stress of $257 \pm 35 \mathrm{MPa}$ (regime $1 / 2$ transition, sample W-1119). Note that the recrystallized grain size is the same within error estimation (see Table 1).

structural changes with decreasing flow stress as the as-is samples (Figures $4 \mathrm{a}-4 \mathrm{~d}$ and $4 \mathrm{e}-4 \mathrm{~h}$ ). The recrystallization microstructures of the water-added samples include dislocation creep regimes 2 (Figures $6 \mathrm{a}$ and $6 \mathrm{~b}$ ) and 3 (Figures $6 \mathrm{c}$ and 7c) of Hirth and Tullis [1992]. The vacuum-dried samples range from the regime 1/regime 2 transition (Figures $6 \mathrm{~d}$ and 7a) to the higher temperature portion of regime 3 (Figure 6f) of Hirth and Tullis [1992]. The sample deformed at the highest flow stress of $247 \pm 40 \mathrm{MPa}$ (Figure 6d) shows inhomogeneously deformed porphyroclasts with undulose extinction, finely serrated grain boundaries, and small numbers of recrystallized grains, which have about the same size as the serrations. With decreasing flow stress and a transition to regime 2 (Figure $6 \mathrm{a}, 168 \pm 50 \mathrm{MPa}$ ), the microstructure is not much different, but the recrystallized grain size is slightly larger and the porphyroclasts have a more elongate shape and contain deformation lamellae. The two samples illustrated in Figures $6 \mathrm{~b}(139 \pm 24 \mathrm{MPa})$ and $6 \mathrm{e}(114 \pm 35 \mathrm{MPa})$ represent conditions close to the regime $2 /$ regime 3 transition, and the amount and size of the recrystallized grains have further increased. The porphyroclasts show more irregular shapes, larger grain boundary sutures, and more subtle internal deformation features than the regime 2 sample of Figure 6a. Regime 3 samples (Figures $6 \mathrm{c}$ and 6f) are characterized by porphyroclasts with irregular shapes and grain boundaries, and almost no optically visible intracrystalline deformation features. The sample illustrated in Figure $6 c(66 \pm 16 \mathrm{MPa})$ has a smaller recrystallized grain size than the one of Figure of $(58 \pm 18 \mathrm{MPa})$, which has some straight grain boundaries and isometric grain shapes.

[27] Using light optical and scanning electron microscopy, no evidence of intergranular melt was found in the samples. For the as-is samples deformed at $1100^{\circ} \mathrm{C}$ a few grain triple junctions showed tiny amounts of melt when analyzed by transmission electron microscopy (TEM). On the basis of relatively poor TEM sampling statistics we estimate that melt fraction is $<0.1 \mathrm{vol} \%$ for samples deformed at $1100^{\circ} \mathrm{C}$ and nonexistent for samples deformed at lower temperatures.

Figure 4. Representative light optical micrographs (crossed polarizers; shortening direction vertical) of as-is deformed BHQ, illustrating the effects of increase in temperature at constant strain rate $\left(\sim 2 \times 10^{-6} \mathrm{~s}^{-1}\right)$ (Figures $\left.4 \mathrm{a}-4 \mathrm{~d}\right)$ and the effects of decrease in strain rate at constant temperature $\left(1100^{\circ} \mathrm{C}\right)$ (Figures $\left.4 \mathrm{e}-4 \mathrm{~h}\right)$. (a) Porphyroclasts with undulose and patchy extinction, bulged grain boundaries, and small subgrains and recrystallized grains of about the same size (lower regime $2,800^{\circ} \mathrm{C}, 32 \%$ strain; sample W-1030). (b) Porphyroclasts with bulged grain boundaries and marginal subgrains and recrystallized grains (upper regime $2,900^{\circ} \mathrm{C}, 34 \%$ strain; sample W-1050). (c) Porphyroclasts with irregular shapes and sutured grain boundaries. Suture width and diameter of internal subgrains and surrounding recrystallized grains are about the same (regime $3,1000^{\circ} \mathrm{C}, 22 \%$ strain; sample W-1024). (d) Porphyroclasts with irregular shape and size and large recrystallized grains (regime $3,1100^{\circ} \mathrm{C}, 31 \%$ strain; sample W-1066). (e) Elongate porphyroclasts with undulose and patchy extinction, bulged grain boundaries, and small recrystallized grains (regime $1 / 2$ transition, $\sim 2 \times 10^{-4} \mathrm{~s}^{-1}, 36 \%$ strain; sample W-1119). (f) Porphyroclasts with irregular shapes, few optically visible internal deformation features, and sutured grain boundaries, surrounded by recrystallized grains (lower regime $3, \sim 2 \times 10^{-5} \mathrm{~s}^{-1}, 46 \%$ strain; sample W1029). (g) Same sample as in Figure $4 \mathrm{~d}$ (regime 3, 2 $\times 10^{-6} \mathrm{~s}^{-1}, 31 \%$ strain; sample W-1066). (h) Grains with isometric shapes and straight grain boundaries. Porphyroclasts and recrystallized grains are almost indistinguishable (upper regime 3 , $\sim 2 \times 10^{-7} \mathrm{~s}^{-1}, 17 \%$ strain; sample W-1126). See text for further microstructural description. 
a)

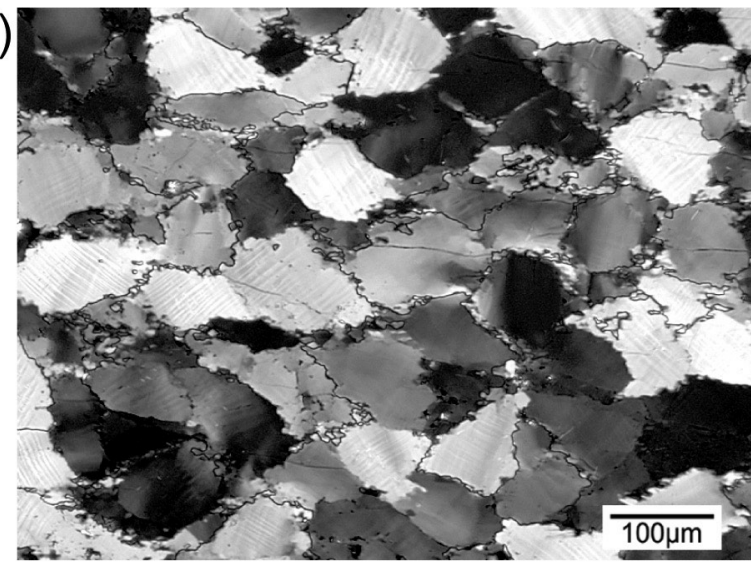

b)

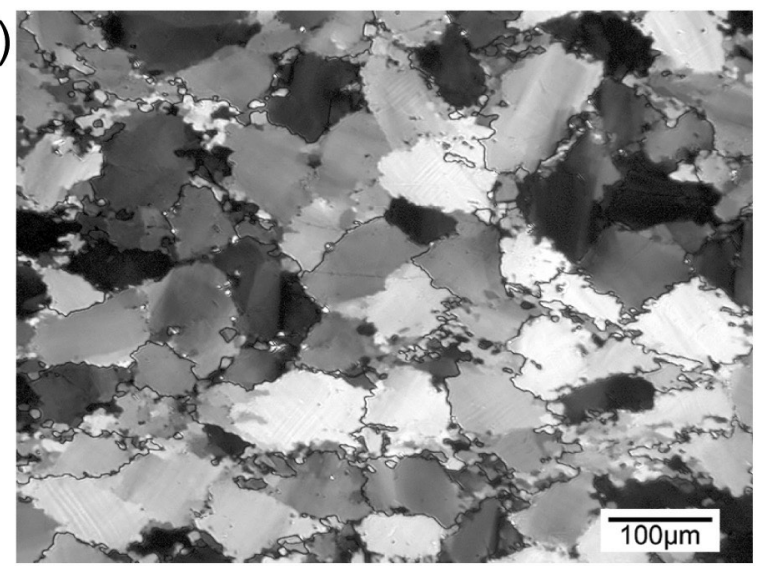

c)

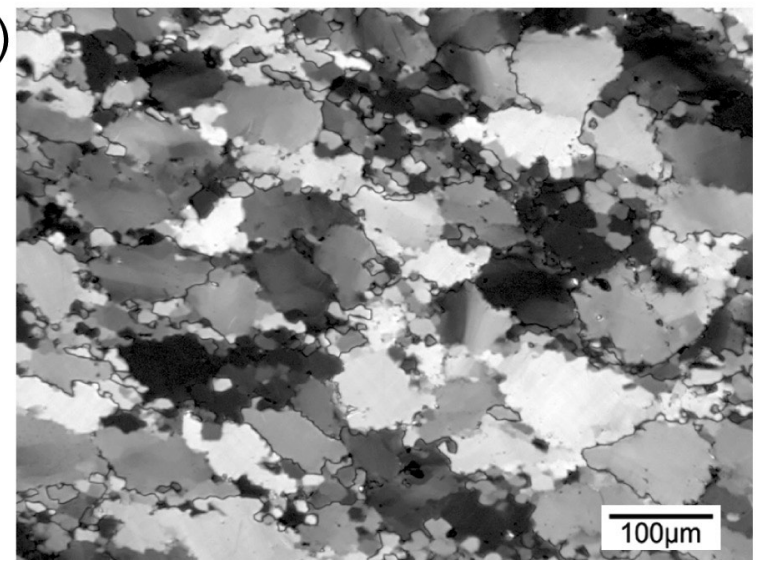

d)

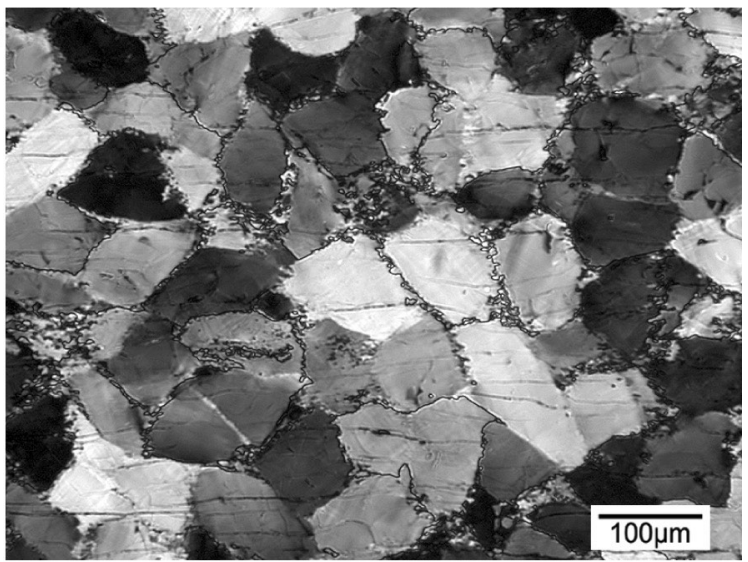

e)

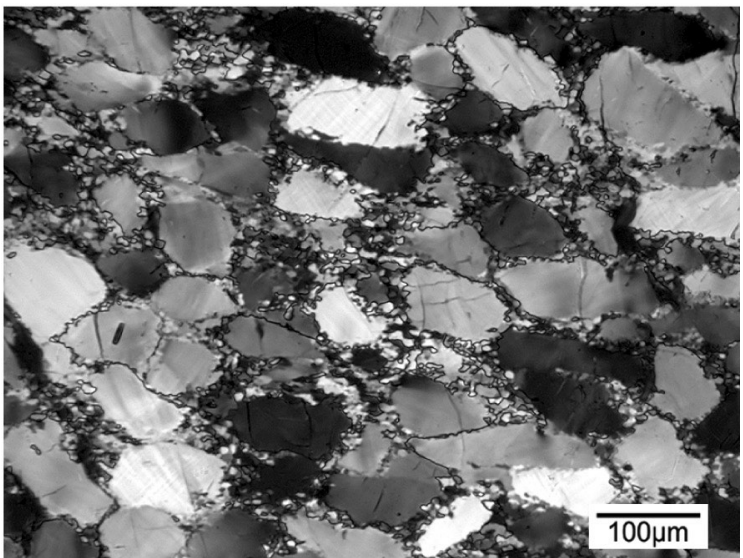

f)

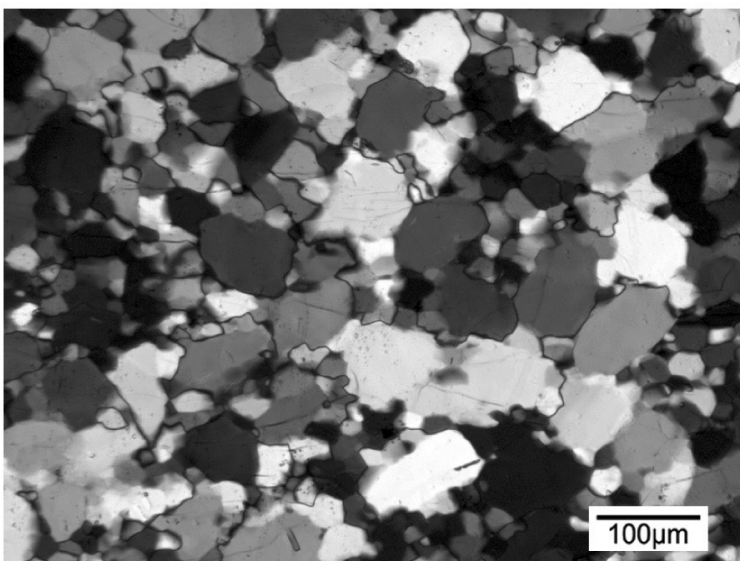

Figure 6. Representative light optical micrographs (crossed polarizers; shortening direction vertical) of water-added (Figures 6a-6c) and vacuum-dried (Figures 6d-6f) deformed BHQ; both columns are characterized by a decrease in flow stress. (a) Porphyroclasts with undulose and patchy extinction, deformation lamellae, and bulged grain boundaries, surrounded by recrystallized grains (regime 2, $168 \pm$ $50 \mathrm{MPa}, 41 \%$ strain; sample W-1082). (b) Porphyroclasts with patchy extinction, bulged grain boundaries, and subgrains and recrystallized grains of about the same size (regime 2/3 transition, $139 \pm$ $24 \mathrm{MPa}, 33 \%$ strain; sample W-1081). (c) Porphyroclasts with few internal deformation features, irregular shapes, and sutured grain boundaries, surrounded by recrystallized grains (regime 3, $66 \pm 16 \mathrm{MPa}$, 29\% strain; sample W-1142). (d) Porphyroclasts with undulose extinction, bulged grain boundaries, and small surrounding recrystallized grains (regime 1/2 transition, $247 \pm 40 \mathrm{MPa}, 25 \%$ strain; sample W-1149). (e) Porphyroclasts with bulged grain boundaries and marginal subgrains and recrystallized grains. Vertical cracks and fractures may be caused by some molten salt intrusion due to the late failure of the run; see text for explanation (regime 2/3 transition, $114 \pm 35 \mathrm{MPa}, 28 \%$ strain; sample W-1141). (f) Porphyroclasts with irregular shapes and large subgrains and recrystallized grains of about the same size (regime 3, 58 $\pm 18 \mathrm{MPa}$, 7\% strain; sample W-1143). 
a)

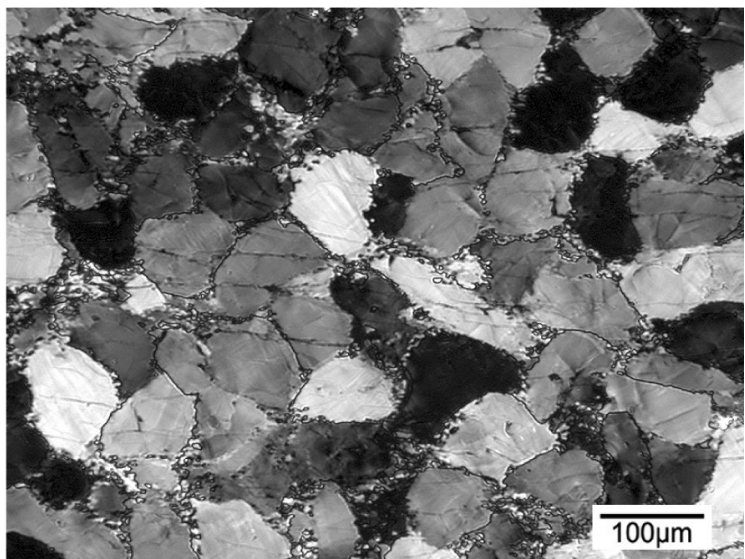

b)

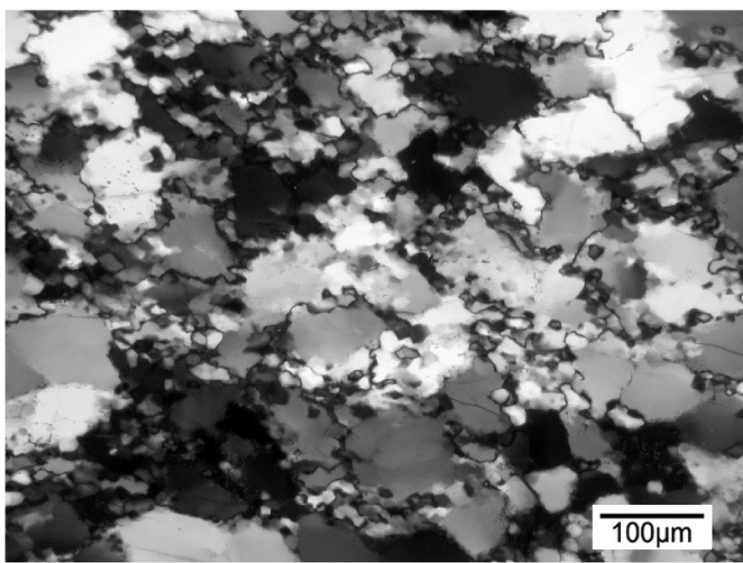

c)

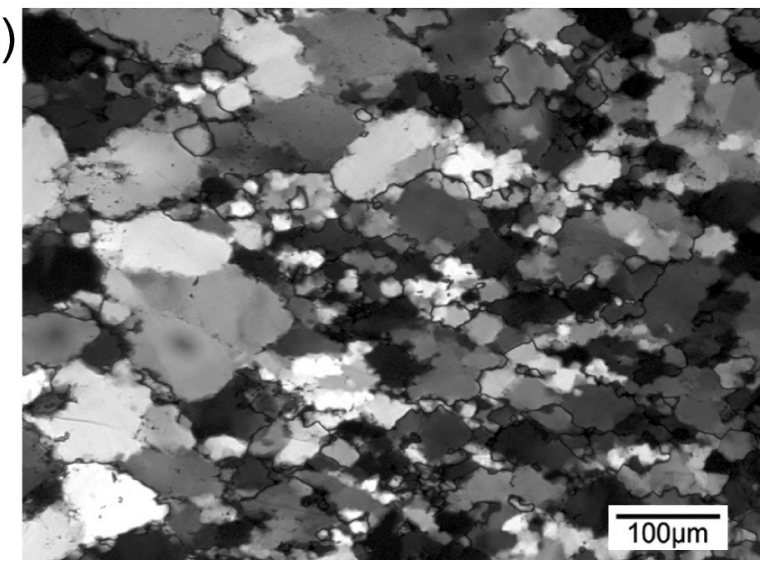

Figure 7. Representative light optical micrographs (crossed polarizers; shortening direction vertical) illustrating microstructures of deformed BHQ as a function of increasing water content (decreasing flow stress) at constant deformation temperature $\left(1000^{\circ} \mathrm{C}\right)$ and strain rate $(\sim 2 \times$ $\left.10^{-6} \mathrm{~s}^{-1}\right)$. (a) Vacuum dried, porphyroclasts with undulose extinction, bulged grain boundaries, and small surrounding recrystallized grains (regime $1 / 2$ transition, $247 \pm 40 \mathrm{MPa}$, 25\% strain; sample W-1149). (b) As is, porphyroclasts with irregular shapes and sutured grain boundaries. Suture width and diameter of internal subgrains and surrounding recrystallized grains are about the same (regime 3, $102 \pm$ $9 \mathrm{MPa}, 22 \%$ strain; sample W-1024). (c) Water added, porphyroclasts with irregular shape and size and large recrystallized grains. Porphyroclasts and new grains can be difficult to distinguish (regime 3, $48 \pm 11 \mathrm{MPa}, 29 \%$ strain; sample W-1172).
[28] To summarize the piezometric data (Tables 1-3) all three sample sets show an increasing recrystallized grain size with decreasing flow stress. The recrystallized grains from the as-is samples range from $3.2 \pm 0.7 \mu \mathrm{m}$ to $46 \pm 15 \mu \mathrm{m}$ at flow stresses between $268 \pm 40 \mathrm{MPa}$ and $34 \pm 16 \mathrm{MPa}$ [Stipp and Tullis, 2003]; those from the water-added samples range from $4.9 \pm 1.2 \mu \mathrm{m}$ to $19.3 \pm 5.1 \mu \mathrm{m}$ at flow stresses between $177 \pm 35 \mathrm{MPa}$ and $48 \pm 11 \mathrm{MPa}$; and those from the vacuum-dried samples range from $4.2 \pm 1.1 \mu \mathrm{m}$ to $19.9 \pm$ $4.9 \mu \mathrm{m}$ at flow stresses between $247 \pm 40 \mathrm{MPa}$ and $58 \pm$ $18 \mathrm{MPa}$. Hence it appears that the same microstructural changes with decreasing flow stress occur with increasing temperature, decreasing strain rate or increasing water content at otherwise constant deformation conditions. The dependence of microstructure and flow stress on water content is displayed in Figures $7 a-7 c$; the three samples illustrated were all deformed at the same temperature and strain rate $\left(1000^{\circ} \mathrm{C}, \sim 2 \times 10^{-6} \mathrm{~s}^{-1}\right)$. However, with increasing water content the flow stress decreases while the recrystallized grain size increases, from $4.2 \pm 1.1 \mu \mathrm{m}$ at $247 \pm$ $40 \mathrm{MPa}$ (Figure $7 \mathrm{a}$, vacuum dried) to $11.6 \pm 3.2 \mu \mathrm{m}$ at $102 \pm 9 \mathrm{MPa}$ (Figure $7 \mathrm{~b}$, as is) and to $19.3 \pm 5.1 \mu \mathrm{m}$ at $48 \pm 11 \mathrm{MPa}$ (Figure 7c, water added). With decreasing flow stress these three microstructures can be correlated to the regime 1/regime 2 transition, to lower regime 3 and to upper regime 3 of Hirth and Tullis [1992], respectively.

[29] Plotting the recrystallized grain size/flow stress data of the vacuum-dried and water-added samples onto the piezometer diagram of Stipp and Tullis [2003] does not indicate any dependence of the piezometer on water content within the error estimation of the data points (Figure 8). The water-added, vacuum-dried, and as-is samples all fit the same piezometric relationship. Addition of water causes a decrease in flow stress and a corresponding increase of the recrystallized grain size, and reduction in water content has the opposite effect. Hence for our experimental conditions, the recrystallized grain size is purely stress-dependent.

\subsection{IR Measurements and Water Analysis}

[30] The BHQ starting material and 13 deformed samples were selected for IR analyses (Table 4). The initial water content of the starting material was also measured by KFT; three different samples (a single rock chip $\sim 4 \mathrm{~mm}$ on a side, three smaller pieces about $1 \mathrm{~mm}$ in diameter and crushed BHQ with a particle size of $<200 \mu \mathrm{m}$; see Table 5 for weights) were heated to temperatures of $1210-1230^{\circ} \mathrm{C}$ (Table 5). The titration results are very consistent, indicating initial water contents between $0.059 \pm 0.004$ and $0.067 \pm$ $0.003 \mathrm{wt} \%$. The single rock piece has the lowest water content and the crushed fraction has the highest, but the variations are within the analytical error (Table 5). Slightly higher values in the crushed material may be due to minor amounts of water adsorbed on the sample during transport from the drying furnace to the KFT apparatus. The average of the three measurements $(0.064 \pm 0.005 \mathrm{wt} \%)$ is taken as the representative water content for the as-is BHQ starting material.

[31] The aim of the IR measurements was to determine the total water signature in the deformed samples and in the starting material, without considering specific sites or defects. Therefore IR analyses were carried out using apertures 20 to 40 times larger than the original grain 


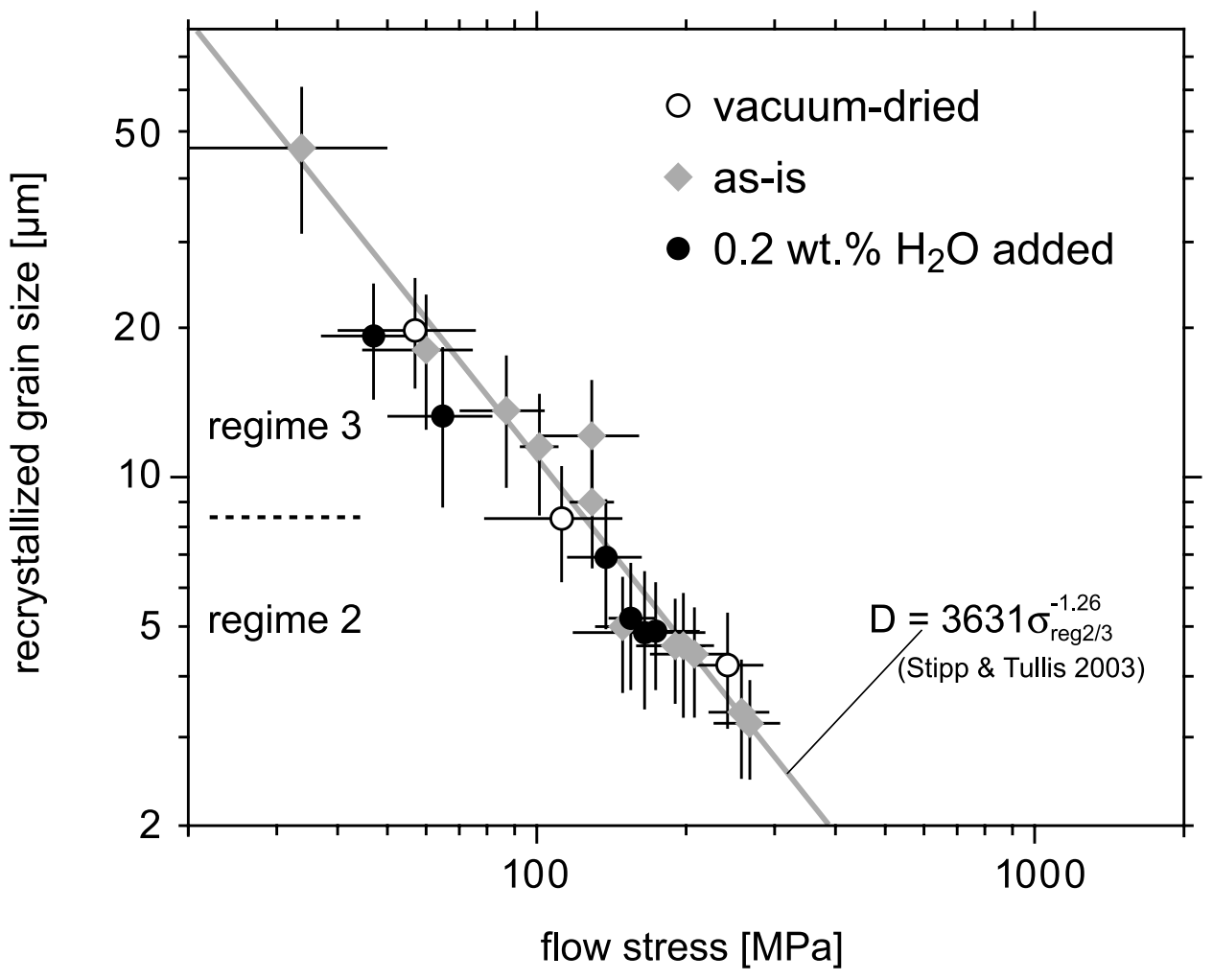

Figure 8. Recrystallized grain size/flow stress data from the water-added and vacuum-dried samples plotted together with the least squares fit calibration of the recrystallized grain size piezometer for the asis samples of dislocation creep regimes 2 and 3 (Stipp and Tullis' [2003] equation is indicated). Within the error estimation of the data there is no detectable effect of water content on the recrystallized grain size piezometer of quartz. See text for further discussion.

diameter, in order to obtain average spectra from the samples, including intragranular water from porphyroclasts and recrystallized grains as well as grain boundary water.

[32] The IR absorption spectrum of the BHQ starting material is characterized by three absorption bands in the range from 3000 to $3700 \mathrm{~cm}^{-1}$ (Figure 9). The broad absorption band centered at approximately $3400 \mathrm{~cm}^{-1}$ is comparable to the $\mathrm{OH}$ absorption band of liquid water and is likely caused by submicron-scale $\mathrm{H}_{2} \mathrm{O}$ clusters and micron-scale fluid inclusions [e.g., Aines and Rossman, 1984], which are abundant in the BHQ starting material (see section 4). Superimposed on the main band are two weaker bands at $3620 \mathrm{~cm}^{-1}$ and $3400 \mathrm{~cm}^{-1}$ which can be attributed to $\mathrm{O}-\mathrm{H}$ stretching vibrations of free silanol groups and hydrogen-bonded silanol groups, respectively [Frondel, 1982; Gallei and Parks, 1972]. There are no sharp peaks in the spectrum characteristic of $\mathrm{O}-\mathrm{H}$ stretching modes of point defects in quartz [cf. Kronenberg, 1994]. Small peaks between 2850 and $2950 \mathrm{~cm}^{-1}$, which occur in the BHQ spectrum and also in a few of the spectra from the deformed samples (Figures 9 and 10), are presumably due to some remnants of epoxy from thin section preparation. Their contribution to the spectra is very small, and so we did not correct for those.

[33] The spectra of the two vacuum-dried samples (W1143, W-1149; Figure 9) only show a weak broad band absorption between 3000 and $3700 \mathrm{~cm}^{-1}$, indicating that not much of the molecular water is left after heating the sample under vacuum and carrying out the deformation experiment. In these two spectra, however, there are two sharp peaks at $3360 \mathrm{~cm}^{-1}$ and at $3382 \mathrm{~cm}^{-1}$. Kats [1962] relates these to hydrogen defects associated with Al substitutions for Si. While the $3382 \mathrm{~cm}^{-1}$ peak exists in spectra from almost all of the samples, the $3360 \mathrm{~cm}^{-1}$ peak is restricted to the vacuum-dried samples. A weak shoulder at $3432 \mathrm{~cm}^{-1}$ (Figure 9) is also related to the substitution of $\mathrm{Al}$ for Si [Wood, 1960; Kats, 1962].

[34] The spectra of the deformed as-is samples display a broad band absorption from 3000 to $3700 \mathrm{~cm}^{-1}$ and the two bands at 3400 and $3620 \mathrm{~cm}^{-1}$ which are all observed in the starting material (Figure 9). The general characteristics of the broad band are very similar for all of the deformed as-is samples, although the signal is significantly weaker than that of the BHQ starting material. The strongest sharp peak at $3382 \mathrm{~cm}^{-1}$ is present in all of the as-is samples (Figure 9). The shoulder at $3432 \mathrm{~cm}^{-1}$ is more prominent than that in the vacuum-dried samples and it strengthens with increasing deformation temperature. In addition, there are two minor peaks at $3585 \mathrm{~cm}^{-1}$ and $3608 \mathrm{~cm}^{-1}$ (Figure 9); according to Kats [1962] these bands could be due to $\mathrm{OH}$ groups associated with potassium.

[35] For the water-added samples deformed at temperatures of $<850^{\circ} \mathrm{C}(\mathrm{W}-1142, \mathrm{~W}-1082$; Figure 10) the broad band signature is very similar to that of the undeformed $\mathrm{BHQ}$, whereas for samples deformed at temperatures of 


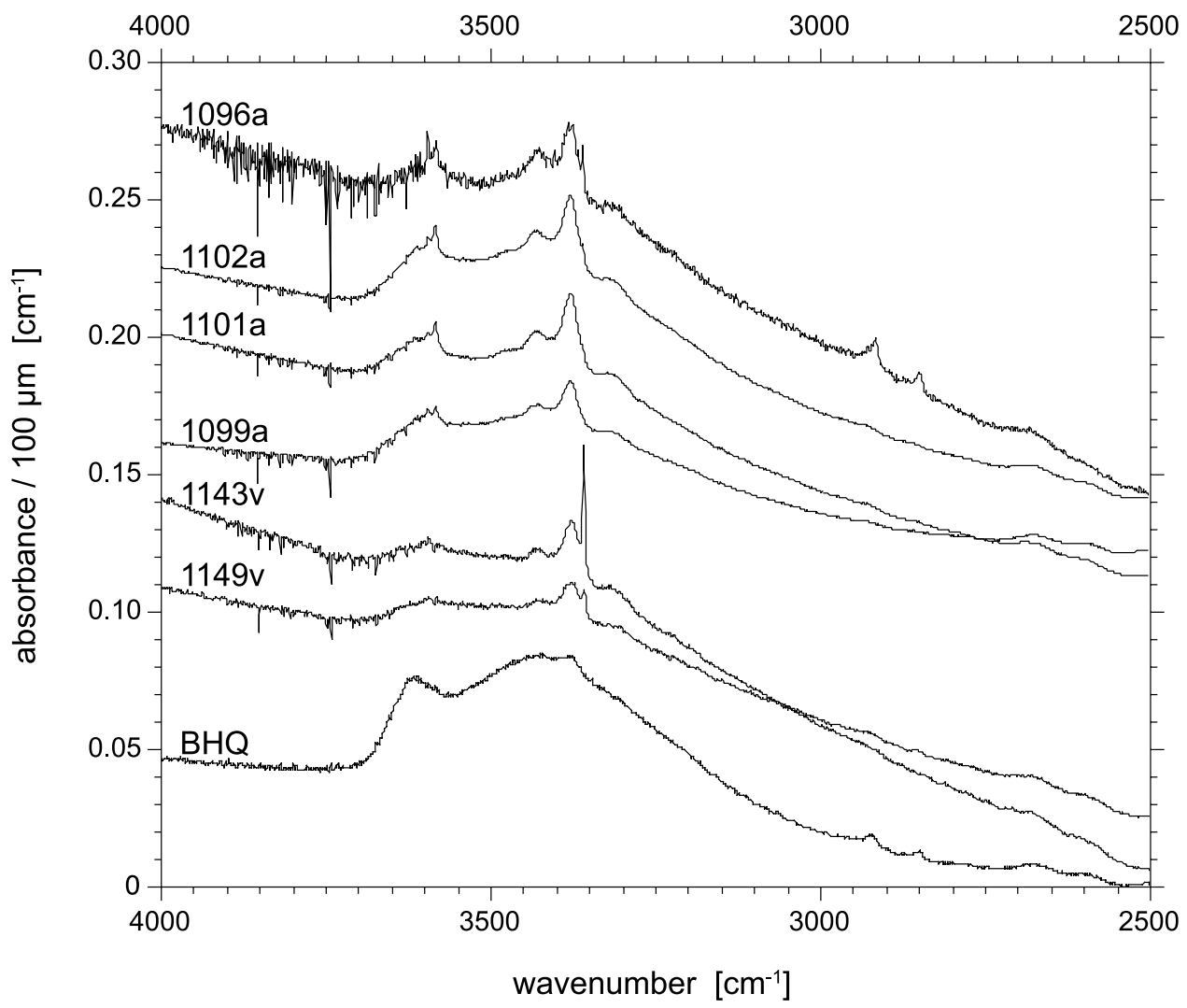

Figure 9. Representative FTIR absorption spectra of the starting material (BHQ), the vacuum-dried (W-1143v, W-1149v), and the as-is (W-1099a, W-1101a, W-1102a, W-1096a) samples. Measurements were carried out with apertures of $2-4 \mathrm{~mm}$ at room temperature. The absorbance is normalized to the thickness of the samples; spectra are plotted with an offset for clarity.

$>850^{\circ} \mathrm{C}$ the bands at $3400 \mathrm{~cm}^{-1}$ and $3620 \mathrm{~cm}^{-1}$ are more enhanced at the expense of the broad band. The most prominent sharp peak at $3382 \mathrm{~cm}^{-1}$ is quite variable in strength in the water-added spectra, whereas the peak at $3432 \mathrm{~cm}^{-1}$ shows a trend of increasing peak height with increasing deformation temperature (Figure 10), similar to the trend for as-is samples. Small peaks are observed at $3585 \mathrm{~cm}^{-1}$ and $3608 \mathrm{~cm}^{-1}$ (Figure 10), similar to what was found in the as-is samples, and these peaks are also more pronounced in samples deformed at higher temperature. No significant difference was found between spectra from samples stored under atmospheric room temperature conditions and those from the same samples kept in an oven at $110^{\circ} \mathrm{C}$ prior to the IR measurement (e.g., W-1081, W-1081d; Figure 10).

[36] For our study and the determination of water contents in deformed quartz aggregates in general, an IR calibration is required for crystalline quartz with a low $(\ll 0.5 \mathrm{wt} \%$ ) water content that is mainly bound in fluid inclusions or adsorbed on grain boundaries. Previous IR calibrations from Paterson [1982] and Libowitzky and Rossman [1997] are based on glasses, water-bearing liquids and hydrous minerals, and hence it has to be tested whether these calibrations are applicable for materials such as used in our study. We have performed a new calibration based on the BHQ starting material for which the water content was measured by KFT. The calibration is based on the total integrated intensity of the $\mathrm{OH}$ stretching vibration band in the range of $3000-3780 \mathrm{~cm}^{-1}, \mathrm{~A}_{\mathrm{OH}}^{*}$, for which the LambertBeer law can be written as [Stolper, 1982]

$$
\mathrm{wt} \% \mathrm{H}_{2} \mathrm{O}=100 \frac{M_{\mathrm{H}_{2} \mathrm{O}} A_{\mathrm{OH}}^{*}}{d \rho \varepsilon_{\mathrm{OH}}^{*}}
$$

where $M_{\mathrm{H}_{2} \mathrm{O}}$ is the molar mass of $\mathrm{H}_{2} \mathrm{O}, d$ is the thickness of the section, $\rho$ is the density of quartz, and $\varepsilon_{\mathrm{OH}}^{*}$ is the integral molar absorption coefficient for the $\mathrm{OH}$ stretching vibration band. Isotropic absorption is assumed for the calibration. Using the KFT data for undeformed BHQ results in an effective absorption coefficient of 24,100 \pm $18001 \mathrm{~mol}^{-1} \mathrm{~cm}^{-2}$. The calculated water contents expressed in $\mathrm{wt} \% \mathrm{H}_{2} \mathrm{O}$ (Table 4) can be converted into wt ppm by multiplying by a factor of 10,000 and into $\mathrm{H} / 10^{6} \mathrm{Si}$ by multiplying by a factor of 7473 . It has to be emphasized that our new calibration is applicable only to quartzite samples with $\mathrm{OH}$ stretching bands having a similar shape as that of the BHQ starting material (Figure 9).

[37] The water contents determined by the Paterson [1982] calibration, which is most commonly used for experimentally deformed quartz aggregates, are approximately 20\% lower than those using the Libowitzky and Rossman [1997] calibration, which are in turn approximately $20 \%$ lower than the values using our new calibration based on BHQ. Because of the analytical restrictions outlined before, the results of the KFT anal- 


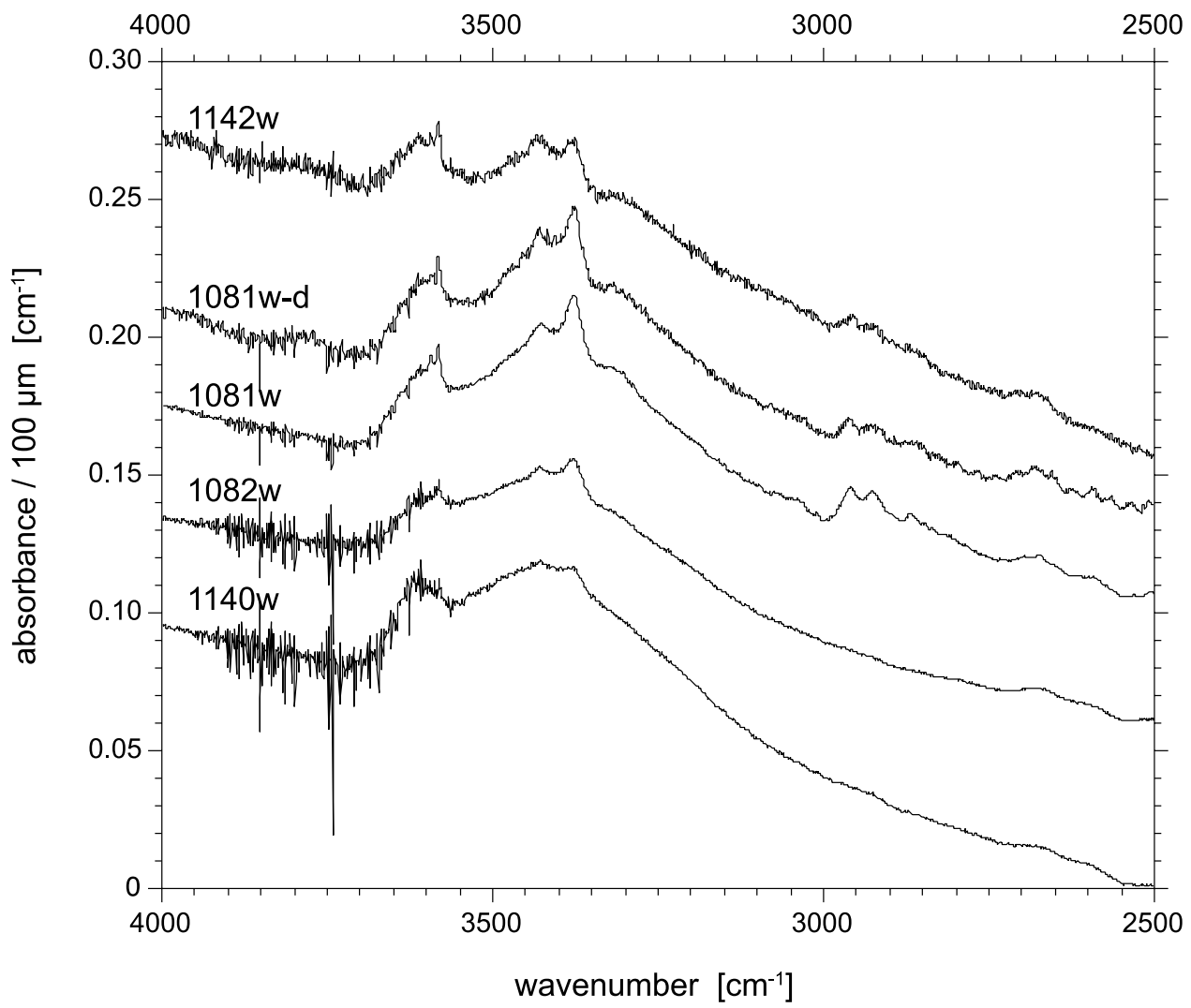

Figure 10. Representative FTIR absorption spectra of the water-added samples. Letter "d" indicates that sample W-1081 was oven dried at $110^{\circ} \mathrm{C}$ for an hour prior to the analysis. Measurements were carried out with apertures of $2-4 \mathrm{~mm}$ at room temperature. The absorbance is normalized to the thickness of the samples; spectra are plotted with an offset for clarity.

ysis represent minimum values of the initial water content (there might be some unextracted water). Thus we assume that the water contents derived from our IR absorption calibration represent minimum values. Although the water contents determined using the different calibrations are quite different, for each calibration the trends between the three sample sets are consistent: the amount of water in vacuumdried samples is less than that in as-is samples, which is less than that in water-added samples. However, the amounts of water measured in the deformed vacuum-dried, as-is, and water-added samples after the experiments are significantly lower than the initial water content of the starting material. We will examine this result in section 4.

\section{Discussion}

\subsection{Estimation of Water Contents and Fugacity}

[38] The two published IR absorption calibrations for the determination of the water content used in our study [Paterson, 1982; Libowitzky and Rossman, 1997] (Table 4) give the same trends, but differing absolute values. Paterson [1982] derived his calibration for the absorption of hydroxyl in various substances including nonsilicates and glasses. The calibration takes into account structurally bound lattice water and hydroxyl, but not liquid water, for which the absorption coefficient is poorly known. The calibration of Libowitzky and Rossman [1997] is based on hydrous silicate and oxide minerals in which the water species are structurally bound, and liquid water is not considered in their calibration. The water content of the BHQ starting material inferred using these two calibrations is significantly lower than that measured by the KFT analysis. Since the KFT analysis can only underestimate the water content of the samples, it appears that neither of these IR absorption calibrations is well suited for the determination of the water contents in our quartzite samples. Despite the fact that the Libowitzky and Rossman [1997] calibration is only pertinent for structurally bound water species and not for liquid water, it gives results closer to the KFT analysis than does the calibration of Paterson [1982], probably due to higher accuracy of the data used in the calibration.

[39] Regardless of the absorption calibration used, the amounts of water measured after our experiments are significantly lower than the initial water content of the starting material (Table 4). This result is puzzling, since we measured bulk spectra in the deformed samples using large aperture sizes, which averaged over many grains and grain boundaries. There are two possible explanations for the differences in water content before and after experiments: (1) water loss during the experiment and (2) water loss during IR sample preparation.

[40] Water loss due to cracking of the jacket can be excluded, because that immediately allows an influx of molten salt which causes a complete stress drop. In addition we infer that diffusional loss of water or hydrogen is not 
important over run durations between a few hours and 250 hours, because there is neither a systematic variation in water content (Tables 1, 2, and 3) nor an increased strength in slow strain rate experiments (Figure 3). However, we cannot rule out the possibility that some hydrogen (from dissociated water) is lost early in the experiments by rapid diffusion through the $\mathrm{Pt} / \mathrm{Ni}$ jacket [cf. Brandes and Brook, 1992]. Kronenberg and Tullis [1984] postulated that the amount of water remaining in their water-added samples was controlled by the $\mathrm{fH}_{2}$ of their solid salt sample assemblies, but our molten salt assemblies are different. It is notable that our water-added BHQ samples display changes in the IR band character, whereas no such changes were described for the water-added Heavitree quartzite samples of Kronenberg and Tullis [1984] [Kronenberg and Wolf, 1990, Figure 6]. In addition, because the BHQ contains very few components which can be oxidized, loss of hydrogen will increase the $\mathrm{fO}_{2}$ inside the capsule, decreasing the driving force for further hydrogen loss. We thus suspect that only very minor water is lost due to hydrogen diffusion within the first hour or so.

[41] While we can only speculate about diffusive loss of hydrogen early in the experiments, considerable water loss during IR sample preparation is very likely. The broad IR band representing molecular water in the starting material was reduced during all the experiments, indicating that fluid inclusions were decrepitated, allowing the water to be transported to grain boundaries. At least part of this grain boundary fluid phase was lost during IR sample preparation.

\subsection{Water Distribution in the Samples}

[42] The BHQ starting material block has areas of two different colors, either white or beige. Fluid inclusions on the scale from $<1 \mu \mathrm{m}$ (hardly recognizable) to $>5 \mu \mathrm{m}$ are abundant in both of these BHQ types as can be seen by light optical microscopy. Selverstone et al. [2003] have analyzed these fluid inclusions and found that white BHQ contains mainly $\mathrm{H}_{2} \mathrm{O}$ inclusions, whereas beige BHQ contains mainly $\mathrm{CO}_{2}$ inclusions, with minor $\mathrm{H}_{2} \mathrm{O}$. We used only the white BHQ in our experiments. The common occurrence of intragranular fluid inclusions suggests that most of the intragranular water is bound in these inclusions and only a minor fraction of water is bound within the crystal lattice, consistent with the IR spectrum of the starting material which is dominated by the broad absorption band assigned to liquid water (Figure 9). Selverstone et al. [2003] observed that the number and especially the size of visible fluid inclusions in BHQ are remarkably reduced after experimental deformation, consistent with the reduction of the broad band component in the IR spectra of our deformed samples. However, the sharp peaks in almost all IR spectra of the deformed samples (Figures 9 and 10) indicate that some specific water-related species are produced during the deformation, because these peaks are absent in the starting material.

[43] There are several possible reasons for the decrease of the broad absorption band in the deformed samples. First, loss of water from fluid inclusions can result from either internal overpressure (confining pressure less than initial internal pressures of the fluid inclusions [Bodnar et al., 1989] or internal underpressure (confining pressure greater than initial internal pressures of the fluid inclu- sions [Sterner and Bodnar, 1989]. In our experiments, initial pressurization (at room temperature and $300^{\circ} \mathrm{C}$ ) causes an internal underpressure, and subsequent heating (above $800^{\circ} \mathrm{C}$ at $1.2-1.5 \mathrm{GPa}$ ) causes an internal overpressure. An extrapolation of the $\mathrm{H}_{2} \mathrm{O}$ isochores [Fisher, 1976; Roedder, 1984] to the final $\mathrm{P} / \mathrm{T}$ conditions of our experiments indicates that an overpressure in the fluid inclusions may develop above $800^{\circ} \mathrm{C}$. Hence, for the total run time of our experiments it can be assumed that $\mathrm{H}_{2} \mathrm{O}$ inclusions with diameters of $>1 \mu \mathrm{m}$ are not stable [e.g., Bodnar et al., 1989]. The IR spectra, especially those of the water-added samples (Figure 10), show a decrease of broad band absorption water with increasing temperature above $\sim 800^{\circ} \mathrm{C}$. Decrepitation of fluid inclusions might also be related to the $\alpha / \beta$ inversion of the quartz host [Bodnar et al., 1989]. Another explanation for a reduced abundance of fluid inclusions in the deformed samples is dynamic recrystallization, which decreases the overall grain size and causes the fluid to move to grain boundaries. Recrystallized grains in our samples tend to have few fluid inclusions, and all our samples show an increase in the amount of dynamic recrystallization with decreasing flow stress (increasing temperature) at otherwise constant deformation conditions, perhaps contributing to the decrease of broad band molecular water with increasing temperature (Figure 10).

[44] Whether or not it is the high $\mathrm{P} / \mathrm{T}$ conditions or the deformation and recrystallization that cause a depletion in the intragranular water content, all the samples show a decrease in the water content compared to the starting material, an effect which was also found by Kronenberg and Wolf [1990] and Post and Tullis [1998] in their quartzite samples. Water might be quickly transported out of the grains via microcracks formed during decrepitation of the fluid inclusions or via dislocation pipe diffusion during deformation [e.g., Tullis and Yund, 1985, 1989; Paterson and Luan, 1990; FitzGerald et al., 1991]. The low water contents of the vacuum-dried samples show that water reduction in these samples is sustained during the whole experiment and that vacuum drying is more efficient for water reduction than deformation of as-is samples.

\subsection{Implications for Hydrolytic Weakening}

[45] Our experiments provide some new information and constraints on the various models for hydrolytic weakening in quartz. Some studies postulate that the water which is present as a free fluid phase along grain boundaries may affect the dislocation creep strength by acting as a buffer for the equilibrium intragranular water content [e.g., Kronenberg and Wolf, 1990] or by controlling the concentration of waterrelated defects via the water fugacity [Post and Tullis, 1998]. These water-related defects have not been identified and may not be quenchable, and there is no indication of them in the IR spectra of our samples. Other studies have suggested that grain boundary water could cause weakening by local solution-precipitation creep [den Brok and Spiers, 1991; den Brok et al., 1994]. However, the dominance of dislocation creep microstructures described above (Figures 4, 5, 6, and 7), which correlate with the dislocation creep regimes of Hirth and Tullis [1992], indicates that solution-precipitation creep does not play a significant role in the deformation of our samples. 
[46] All previous experimental studies lack reliable measurements of the water content of the deformed samples. Most of these studies [e.g., den Brok et al., 1994; Post and Tullis, 1998] are based on intragranular IR measurements using the calibration of Paterson [1982]. A shortcoming of the Paterson [1982] calibration and the resulting underestimation in water content has been discussed above. Kronenberg and Wolf [1990] used a calibration of broad band IR absorptions based on measured water contents of wet synthetic quartz crystals, which is not appropriate for their analysis of quartzite samples due to the differences in band character between synthetic and natural quartz. In addition, in previous studies the sampling statistics used to obtain an average intragranular water content are questionable. For example, den Brok et al. [1994] analyzed 6 to 15 grains in each of seven samples, and Post and Tullis [1998] analyzed 11 to 14 grains in each of five samples. Water contents in different grains within each sample, however, vary by approximately 1 order of magnitude in $\mathrm{ppm} \mathrm{H} / \mathrm{Si}$, not allowing a meaningful average intragranular water content to be inferred. Hence these studies only allow one to draw conclusions about local intragranular water contents and distributions. Although our study has contributed some new information and constraints, it does not fully constrain the water distribution within the deformed samples. A detailed quantification of the intra and intergranular water is required, including an investigation of fluid inclusions, water defects and dislocation substructures before and after deformation of the samples.

[47] Our study also did not control the water fugacity in all the samples, and thus has not fully constrained the effect of water fugacity on the recrystallized grain size piezometer. However, the water-added samples almost certainly had free water along the grain boundaries and thus had a water fugacity given by confining pressure and temperature [e.g., Tödheide, 1972; Kerrick and Jacobs, 1981], whereas the vacuum-dried samples had no free water present and thus had a much lower water fugacity. In section 4.4 we come back to the main focus of our study, the determination of water effects on the recrystallized grain size piezometer for quartz.

\subsection{Effects on the Piezometer?}

[48] The results of our study show that water does not have an independent effect on the recrystallized grain size piezometer of quartz, within our stress and grain size errors and for our experimental conditions. As yet, we do not understand the microphysical effects of water on recrystallized grain size and flow stress. In addition, it is not clear to us why an increase in water content and/or fugacity causes the same microstructural changes as an increase in temperature or a decrease in strain rate. At present, we can only refer to the empirical flow law of dislocation creep [e.g., Kohlstedt et al., 1995; Hirth et al., 2001], which indicates that corresponding changes of temperature, strain rate or water fugacity have comparable effects on the steady state dislocation creep flow stress.

[49] There are no other piezometer data for quartz with which we can compare our results. The microstructural and mechanical data in previous experimental piezometer studies are too inaccurate, as demonstrated by the laboratory work of Gleason and Tullis [1993] or extrapolations to deformation conditions of natural mylonites [Stipp et al., 2002a]. Consistent with previous studies on the water weakening effect [e.g., Griggs and Blacic, 1965; Post and Tullis, 1998], our experiments show that with increasing initial water content over a range up to $\sim 0.25 \mathrm{wt} \%$, the flow stress decreases at constant temperature and strain rate, or the strain rate decreases at constant temperature and flow stress. Similarly, there is a change in dislocation creep regime, i.e., from regime 2 to regime 3 [e.g., Hirth and Tullis, 1992], with increasing water content at otherwise constant deformation conditions.

[50] Experimental studies on olivine report contradictory results concerning the influence of water on the recrystallized grain size piezometer relationship. Van der Wal et al. [1993] found no water dependence in their experiments at $0.3 \mathrm{GPa}$ confining pressure and $1100-1400^{\circ} \mathrm{C}$, while Jung and Karato [2001] found a water dependence in their experiments at $2.0 \mathrm{GPa}$ and $1200-1300^{\circ} \mathrm{C}$. Both studies have some shortcomings concerning either the mechanical data (indirect stress estimation via dislocation densities [Jung and Karato, 2001]) or the final water contents of the samples (Van der Wal et al. [1993] present no measurements of the water contents and water may partition into intergranular melts in their experiments; Jung and Karato [2001] present no data or description of how water contents were determined). Despite the discrepancy, both of the olivine studies agree that the grain boundary migration rate is the limiting parameter controlling the recrystallized grain size. An increase in the grain boundary migration rate for olivine is caused by increased water content, as has been shown by Chopra and Paterson [1981, 1984] and Karato et al. [1986]. Hence the recrystallized grain size is related to the water content (or water fugacity) via the grain boundary migration rate. Alternatively, the water dependence of the rate of dislocation climb may determine the recrystallized grain size; the experiments of $\mathrm{Mei}$ and Kohlstedt [2000a] show that water fugacity (i.e., $\mathrm{OH}$ concentration) controls the diffusivity of point defects and therefore the rate of dislocation climb and creep [e.g., Mei and Kohlstedt, 2000b].

[51] The microstructures of our quartzite samples indicate that they were deformed in dislocation creep regimes 2 and 3 (Figures 4, 6, and 7). Although subgrain rotation recrystallization was reported to be dominant in dislocation creep regime 2 of quartz [Hirth and Tullis, 1992], both subgrain rotation and grain boundary migration tend to be concurrent processes during dynamic recrystallization [e.g., Drury and Urai, 1990; Stipp et al., 2002b; Tullis, 2002]. In the following, we consider the effect of water on theoretical piezometer models of both grain boundary migration and subgrain rotation recrystallization.

[52] For the case of grain boundary migration recrystallization, assuming a dynamic balance between the processes of grain size reduction and grain size increase by grain boundary migration, the recrystallized grain size D can be expressed by the following relationship (e.g., Derby and Ashby [1987] and Derby [1990], as one possible piezometer model):

$$
D=\frac{C \varepsilon_{c r} \nu}{\dot{\varepsilon}}
$$


where $\dot{\varepsilon}$ is the steady state strain rate, $\varepsilon_{c r}$ is the critical strain for recrystallization, $v$ is the grain boundary migration rate and $\mathrm{C}$ is a constant. If dislocation creep is accommodated by grain boundary migration recrystallization, the lack of dependence on water that we observe experimentally would require simultaneous changes of strain rate and grain boundary migration rate by the same factor [cf. Van der Wal et al., 1993]. Indeed, it has been observed experimentally that both strain rate [e.g., Karato et al., 1986; Luan and Paterson, 1992] and grain boundary migration rate [e.g., Tullis and Yund, 1982; Urai et al., 1986] depend on water content. Both rates increase with increasing water content, but if or how they do correspond has not yet been investigated.

[53] Alternatively, if dislocation creep is climb controlled, an increase in water fugacity may increase the diffusivity of defects in the crystal lattice, which would facilitate the formation of larger subgrains; then the climb-controlled grain size increase would need to be balanced somehow by a faster strain rate and so a higher rate of dislocation production neglecting any changes in dislocation glide. Theoretical piezometer models of subgrain rotation recrystallization are based on a dynamic balance between the rate of dislocation tangling and the rate of dislocation annihilation [Edward et al., 1982] or between nucleation and growth of subgrains [Shimizu, 1998]. We consider that in our samples subgrain rotation and grain boundary migration operated concurrently; thus piezometer models of pure grain boundary migration or pure subgrain rotation recrystallization can be regarded as end-members. An ideal theoretical model for quartz should incorporate both processes.

[54] Incorporation of grain size sensitive creep mechanisms into the recrystallized grain size piezometer model as has been theoretically modeled in the field boundary hypothesis [De Bresser et al., 1998, 2001] and experimentally shown for Magnox (a magnesium alloy [De Bresser et al., 1998]) is probably not appropriate for quartz. Grain size sensitive creep of quartz has only been reported for deformation experiments on extremely fine-grained aggregates at very dry conditions [Rutter and Brodie, 2004]. Extrapolation to natural strain rates results in unrealistically fine grain sizes at high deformation temperatures [Brodie and Rutter, 2000]. Hence a paleopiezometer for the recrystallized grain size of quartz does not need to consider grain size sensitive creep mechanisms. Furthermore, an independent effect of temperature on the quartz grain size piezometer is also negligible [Stipp and Tullis, 2003]. In the present study we did not observe an independent effect of water within the error estimates of our data set over the range of our experimental conditions and the range of water contents used. Thus field geologists need not consider different temperatures or the possibility of varying water contents in their quartz rock samples when applying the recrystallized grain size piezometer of Stipp and Tullis [2003], as long as the microstructures clearly indicate deformation by dislocation creep.

\section{Summary and Conclusions}

[55] Changes of the dynamic recrystallization microstructure in experimentally deformed Black Hills quartzite correlate with changes in flow stress, but are independent of temperature, strain rate and water content. Measurements of the total water content of the deformed samples using IR absorption spectra indicate that the amount of water in vacuum-dried samples is less than that in as-is samples, which is less than that in water-added samples, which is less than that in the starting material. Our IR calibration is based on the KFT analysis of the starting material, and comparison with previously used IR calibrations demonstrates that the latter systematically underestimate the water content of Black Hills quartzite. Only relative differences in water content within a sample set are reliable when solely using these previous IR calibrations. During deformation of Black Hills quartzite decrepitation of aqueous fluid inclusions and transport of the water via microcracking or dislocation pipe diffusion causes an increase of the free fluid phase along the grain boundaries, which probably controls water fugacity and flow stress during the experiments. The differences in water content before and after the experiments can be explained by some loss of hydrogen from dissociated water very early in the deformation experiments plus loss of water during IR sample preparation. Vacuum-dried, as-is, and water-added samples all have the same recrystallized grain size/flow stress relationship. Hence there is no independent water effect on the piezometric relationship, and paleostress estimates on natural mylonites need not consider differences in water content when applying the recrystallized grain size piezometer of quartz.

[56] Acknowledgments. We are grateful to R. Yund and C. Holyoke for many contributions to this research; we also thank R. Heilbronner, E. Rybacki, J. Selverstone, and H. Stünitz for helpful discussions, W. Collins and W. Tschudin for sample preparation, and D. Lemke for carrying out the KFT analyses. We appreciate the review by S.-I. Karato and especially the thorough and stimulating review by A. Kronenberg which significantly improved the manuscript. Supported by Swiss NF 81BS-63210, US NSF EAR-0106850, and 0208150 and a Novartis stipendium to M.S.

\section{References}

Aines, R. D., and G. R. Rossman (1984), Water in minerals-A peak in the infrared, J. Geophys. Res., 89, 4059-4071.

Bäeta, R. D., and K. H. G. Ashbee (1970), Mechanical deformation of quartz-I. Constant strain-rate compression experiments, Philos. Mag., $22,601-623$.

Balderman, M. (1974), The effect of strain rate and temperature on the yield point of hydrolytically weakened synthetic quartz, J. Geophys. Res., 79, $1647-1652$.

Behrens, H., C. Romano, M. Nowak, F. Holtz, and D. B. Dingwell (1996), Near-infrared spectroscopic determination of water species in glasses of system $\mathrm{MAlSi}_{3} \mathrm{O}_{8}(\mathrm{M}=\mathrm{Li}, \mathrm{Na}, \mathrm{K})$ : An interlaboratory study, Chem. Geol., 128, 41-63.

Blacic, J. D., and J. M. Christie (1984), Plasticity and hydrolytic weakening of quartz single crystals, J. Geophys. Res., 89, 4223-4239.

Bodnar, R. J., P. R. Binns, and D. L. Hall (1989), Synthetic fluid inclusions-VI. Quantitative evaluation of the decrepitation behaviour of fluid inclusions in quartz at one atmosphere confining pressure, J. Metamorph. Geol., 7, 229-242.

Brandes, E. A., and G. B. Brook (Eds.) (1992), Smithells Metals Reference Book, 7th ed., 1800 pp., Elsevier, New York.

Brodie, K. H., and E. H. Rutter (2000), Deformation mechanisms and rheology: Why marble is weaker than quartzite, J. Geol. Soc. London, 157, 1093-1096.

Chopra, P. N., and M. S. Paterson (1981), The experimental deformation of dunite, Tectonophysics, 78, 453-473.

Chopra, P. N., and M. S. Paterson (1984), The role of water in the deformation of dunite, J. Geophys. Res., 89, 7861-7876.

De Bresser, J. H. P., C. J. Peach, J. P. J. Reijs, and C. J. Spiers (1998), On dynamic recrystallization during solid state flow: Effects of stress and temperature, Geophys. Res. Lett., 25, 3457-3460.

De Bresser, J. H. P., J. H. Ter Heege, and C. H. Spiers (2001), Grain size reduction by dynamic recrystallization: $\mathrm{Can}$ it result in major rheological weakening?, Int. J. Earth Sci., 90, 28-45. 
den Brok, S. W. J., and C. J. Spiers (1991), Experimental evidence for water weakening of quartzite by microcracking plus solution-precipitation creep, J. Geol. Soc. London, 148, 541-548.

den Brok, B., J. Meinecke, and K. Röller (1994), Fourier transform IRdetermination of intragranular water content in quartzites experimentally deformed with and without added water in the ductile deformation field, J. Geophys. Res., 99, 19,821-19,828.

Derby, B. (1990), Dynamic recrystallization and grain size, in Deformation Processes in Minerals, Ceramics and Rocks, edited by D. J. Barber and P. G. Meredith, pp. 354-364, CRC Press, Boca Raton, Fla.

Derby, B., and M. F. Ashby (1987), On dynamic recrystallization, Scr. Metall., 21, 879-884.

Drury, M. R., and J. L. Urai (1990), Deformation-related recrystallization processes, Tectonophysics, 172, 235-253.

Drury, M. R., F. J. Humphreys, and S. H. White (1985), Large strain deformation studies using polycrystalline magnesium as a rock analogue. part II: Dynamic recrystallisation mechanisms at high temperatures, Phys. Earth Planet. Inter., 40, 208-222.

Edward, G. H., M. A. Etheridge, and B. E. Hobbs (1982), On the stress dependence of subgrain size, Textures Microstruct., 5, 127-152.

Fisher, J. R. (1976), The volumetric properties of $\mathrm{H}_{2} \mathrm{O}-\mathrm{A}$ graphical portrayal, J. Res. U.S. Geol. Surv., 4, 189-193.

FitzGerald, J. D., J. N. Boland, A. C. McLaren, A. Ord, and B. E. Hobbs (1991), Microstructures in water-weakened single crystals of quartz, J. Geophys. Res., 96, 2139-2155.

Frondel, C. (1982), Structural hydroxyl in chalcedony (type-B quartz), Am Mineral., 67, 1248-1257.

Gallei, E., and G. A. Parks (1972), Evidence for surface hydroxyl groups in attenuated total reflectance spectra of crystalline quartz, J. Colloid Interface Sci., 38, 650-651.

Gleason, G. C., and J. Tullis (1993), Improving flow laws and piezometers for quartz and feldspar aggregates, Geophys. Res. Lett., 20, 2111-2114.

Gleason, G. C., and J. Tullis (1995), A flow law for dislocation creep of quartz aggregates determined with the molten salt cell, Tectonophysics, $247,1-23$.

Green, H. W., II, and R. S. Borch (1989), A new molten-salt cell for precision stress measurement at high pressure, Eur. J. Mineral., 1, $213-219$

Griggs, D. T., and J. D. Blacic (1964), The strength of quartz in the ductile regime, Eos Trans. $A G U, 45,102-103$

Griggs, D. T., and J. D. Blacic (1965), Quartz: Anomalous weakness of synthetic crystals, Science, 147, 292-295.

Hirth, G., and J. Tullis (1992), Dislocation creep regimes in quartz aggregates, J. Struct. Geol., 14, 145-159.

Hirth, G., C. Teyssier, and W. J. Dunlap (2001), An evaluation of quartzite flow laws based on comparisons between experimentally and naturally deformed rocks, Int. J. Earth Sci., 90, 77-87.

Hobbs, B. E., A. C. McLaren, and M. S. Paterson (1972), Plasticity of single crystals of synthetic quartz, in Flow and Fracture of Rocks, Geophys. Monogr. Ser., vol. 16, edited by H. C. Heard et al., pp. 29-53, AGU, Washington, D. C

Jaoul, O., J. Tullis, and A. Kronenberg (1984), The effect of varying water contents on the creep-behavior of Heavitree quartzite, J. Geophys. Res., $89,4298-4312$

Jung, H., and S.-I. Karato (2001), Effects of water on dynamically recrystallized grain-size of olivine, J. Struct. Geol., 23, 1337-1344.

Karato, S.-I., M. S. Paterson, and J. D. FitzGerald (1986), Rheology of synthetic olivine aggregates: Influence of grain size and water, J. Geophys. Res., 91, 8151-8176.

Kats, A. (1962), Hydrogen in alpha-quartz, Philips Res. Rep., 17, 133-195, $201-279$

Kekulawala, K. R. S. S., M. S. Paterson, and J. N. Boland (1978), Hydrolytic weakening in quartz, Tectonophysics, 46, T1-T6.

Kerrick, D. M., and G. K. Jacobs (1981), A modified Redlich-Kwong equation for $\mathrm{H}_{2} \mathrm{O}, \mathrm{CO}_{2}$, and $\mathrm{H}_{2} \mathrm{O}-\mathrm{CO}_{2}$ mixtures at elevated pressures and temperatures, Am. J. Sci., 281, 735-767.

Koch, P. S., J. M. Christie, A. Ord, and R. P. George (1989), Effect of water on the rheology of experimentally deformed quartzite, J. Geophys. Res. 94, 13975-13996.

Kohlstedt, D. L., and M. S. Weathers (1980), Deformation induced microstructures, paleopiezometers and differential stresses in deeply eroded fault zones, J. Geophys. Res., 85, 6269-6285.

Kohlstedt, D. L., B. Evans, and S. J. Mackwell (1995), Strength of the lithosphere: Constraints imposed by laboratory experiments, J. Geophys. Res., 100, 17,587-17,602.

Kronenberg, A. K. (1994), Hydrogen speciation and chemical weakening of quartz, in Silica: Physical Behavior, Geochemistry, and Materials Applications, Rev. Mineral., vol. 29, edited by P. J. Heaney, C. T. Prewitt and G. V. Gibbs, pp. 123-176, Mineral. Soc. of Am., Washington, D. C.
Kronenberg, A. K., and J. Tullis (1984), Flow strengths of quartz aggregates: Grain size and pressure effects due to hydrolytic weakening, J. Geophys. Res., 89, 4281-4297.

Kronenberg, A. K., and G. H. Wolf (1990), Fourier transform infrared spectroscopy determinations of intragranular water content in quartzbearing rocks: Implications for hydrolytic weakening in the laboratory and within the Earth, Tectonophysics, 172, 255-271.

Kronenberg, A. K., S. H. Kirby, R. D. Aines, and G. R. Rossman (1986), Solubility and diffusional uptake of hydrogen in quartz at high water pressures: Implications for hydrolytic weakening, J. Geophys. Res., 91, $2723-2744$

Libowitzky, E., and G. R. Rossman (1997), An IR absorption calibration for water in minerals, Am. Mineral., 82, 1111-1115.

Linker, M. F., and S. H. Kirby (1981), Anisotropy in the rheology of hydrolytically weakened synthetic quartz crystals, in Mechanical Behavior of Crustal Rocks, The Handin Volume, Geophys. Monogr. Ser. vol. 24, edited by N. L. Carter et al., pp. 29-48, AGU, Washington, D. C.

Luan, F. C., and M. S. Paterson (1992), Preparation and deformation of synthetic aggregates of quartz, J. Geophys. Res., 97, 301-320.

Mainprice, D. H., and M. S. Paterson (1984), Experimental studies of the role of water in the plasticity of quartzites, J. Geophys. Res., 89, 42574269

Mei, S., and D. L. Kohlstedt (2000a), Influence of water on plastic deformation of olivine aggregates: 1. Diffusion creep regime, J. Geophys. Res., $105,21,457-21,469$

Mei, S., and D. L. Kohlstedt (2000b), Influence of water on plastic deformation of olivine aggregates: 2. Dislocation creep regime, J. Geophys. Res., 105, 21,471-21,481.

Mercier, J.-C. C., D. A. Anderson, and N. L. Carter (1977), Stress in the lithosphere: Inferences from steady state flow of rocks, Pure Appl. Geophys., 115, 199-226.

Panozzo Heilbronner, R., and C. Pauli (1993), Integrated spatial and orientation analysis of quartz c-axes by computer-aided microscopy, J. Struct. Geol., 15, 369-382.

Paterson, M. S. (1982), The determination of hydroxyl by infrared-absorption in quartz, silicate-glasses and similar materials, Bull. Mineral., 105, $20-29$

Paterson, M. S. (1989), The interaction of water with quartz and its influence in dislocation flow-an overview, in Rheology of Solids and of the Earth, edited by S.-I. Karato and M. Toriumi, pp. 107-142, Oxford Univ. Press, New York.

Paterson, M. S., and F. C. Luan (1990), Quartzite rheology under geological conditions, in Deformation Mechanisms, Rheology and Tectonics, edited by R. J. Knipe, and E. H. Rutter, Geol. Soc. Spec. Publ., 54, 299-307. Post, A., and J. Tullis (1998), The rate of water penetration in experimentally deformed quartzite; implications for hydrolytic weakening, Tectonophysics, 295, 117-137.

Post, A. D., J. Tullis, and A. Yund (1996), Effects of chemical environmen on dislocation creep of quartzite, J. Geophys. Res., 101, 22,143-22,155.

Renner, J., B. Stöckhert, A. Zerbian, K. Röller, and F. Rummel (2001), An experimental study into the rheology of synthetic polycrystalline coesite aggregates, J. Geophys. Res., 106, 19,411-19,429.

Roedder, E. (1984), Fluid Inclusions, Rev. Mineral., vol. 12, 644 pp., Mineral. Soc. of Am., Washington, D. C.

Rutter, E. H., and K. H. Brodie (2004), Experimental grain size-sensitive flow of hot-pressed Brazilian quartz aggregates, J. Struct. Geol., 26, $2011-2023$

Rybacki, E., J. Renner, K. Konrad, W. Harbott, F. Rummel, and B. Stöckhert (1998), A servohydraulically-controlled deformation apparatus for rock deformation under conditions of ultra-high pressure metamorphism, Pure Appl. Geophys., 152, 579-606.

Rybacki, E., K. Konrad, J. Renner, M. Wachmann, B. Stöckhert, and F. Rummel (2003), Experimental deformation of synthetic aragonite marble, J. Geophys. Res., 108(B3), 2174, doi:10.1029/2001JB000694.

Selverstone, J., J. Tullis, and C. Holyoke (2003), Variations in quartzite rheology as a function of metamorphic fluid composition: Results of coupled fluid inclusion and experimental studies, Geol. Soc. Am. Abstr. Programs, 35, 91

Shimizu, I. (1998), Stress and temperature dependence of recrystallized grain size: A subgrain misorientation model, Geophys. Res. Lett., 25 4237-4240.

Sterner, S. M., and R. J. Bodnar (1989), Synthetic fluid inclusions-VII. Reequilibration of fluid inclusions in quartz during laboratory-simulated metamorphic burial and uplift, J. Metamorph. Geol., 7, 243-260.

Stipp, M., and J. Tullis (2003), The recrystallized grain size piezometer for quartz, Geophys. Res. Lett., 30(21), 2088, doi:10.1029/ 2003GL018444.

Stipp, M., H. Stünitz, R. Heilbronner, S. M. Schmid (2002a), Dynamic recrystallization of quartz: Correlation between natural and experimenta 
conditions, in Deformation Mechanisms, Rheology and Tectonics: Current Status and Future Perspectives, edited by S. De Meer et al., Geol. Soc. Spec. Publ., 200, 171-190.

Stipp, M., H. Stünitz, R. Heilbronner, and S. M. Schmid (2002b), The eastern Tonale fault zone: A "natural laboratory" for crystal plastic deformation of quartz over a temperature range from $250^{\circ} \mathrm{C}$ to $700^{\circ} \mathrm{C}, J$. Struct Geol., 24, $1861-1884$.

Stolper, E. M. (1982), Water in silicate glasses: An infrared spectroscopic study, Contrib. Mineral. Petrol., 81, 1-17.

Tödheide, K. (1972), Water at high temperatures and pressures, in Water- $A$ Comprehensive Treatise 1, edited by F. Franks, pp. 463-514, Springer, New York.

Tullis, J. (2002), Deformation of granitic rocks: Experimental studies and natural examples, in Plastic Deformation of Minerals and Rocks, Rev. Mineral. Geochem., vol. 51, edited by S.-I. Karato and H. R. Wenk, pp. 51-95, Mineral. Soc. of Am., Washington, D. C.

Tullis, J., and R. A. Yund (1982), Grain-growth kinetics of quartz and calcite aggregates, J. Geol., 90, 301-318.

Tullis, J., and R. A. Yund (1985), Hydrolytic weakening of quartz aggregates: Requirement for rapid water penetration, Eos Trans. AGU, 66 , 1084.

Tullis, J., and R. A. Yund (1989), Hydrolytic weakening of quartz aggregates - the effects of water and pressure on recovery, Geophys. Res. Lett., $16,1343-1346$
Tullis, J., G. L. Shelton, and R. A. Yund (1979), Pressure-dependence of rock strength-Implications for hydrolytic weakening, Bull. Mineral., $102,110-114$.

Urai, J. L., W. D. Means, and G. S. Lister (1986), Dynamic recrystallization of minerals, in Mineral and Rock Deformation: Laboratory Studies, Geophys. Monogr. Ser., vol. 36, pp. 161-199, edited by B. E. Hobbs and H. C. Heard, AGU, Washington, D. C.

Van der Wal, D., P. Chopra, M. Drury, and J. Fitz Gerald (1993), Relationship between dynamically recrystallized grain size and deformation conditions in experimentally deformed olivine rocks, Geophys. Res. Lett., 20, $1479-1482$

White, S. (1979), Grain and sub-grain size variations across a mylonite zone, Contrib. Mineral. Petrol., 70, 193-202.

Wood, D. L. (1960), Infrared absorption of defects in quartz, J. Phys. Chem. Solids, 13, 326-336.

H. Behrens, Institut für Mineralogie, Universität Hannover, Welfengarten 1, D-30167, Hannover, Germany.

M. Stipp, Geological Institute, Albert-Ludwigs-University, Albertstrasse 23b, D-79104 Freiburg, Germany. (michael.stipp@geologie.uni-freiburg. de)

J. Tullis, Department of Geological Sciences, Brown University, P.O. Box 1846, Providence, RI 02912, USA. 